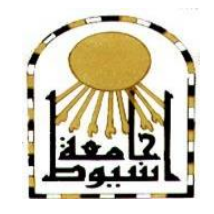

كلية التربية

كلية معتدة من الهيئة القومية لضمان جودة التعليم

مجلة دراسات في مجال الارشاد النفسي والتربوي- كلية التربية- جامعة أسيوط

$=====$

ضعـف اللغة النوعي لذوى صعوبات التعلم النمائية

الثانوية لمرحلة رياض الأطفال في ضوء بعض المتغير ات لات الديموجر افية

\title{
8), (9)
}

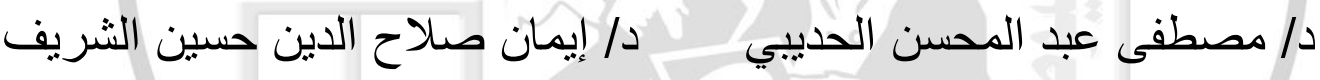

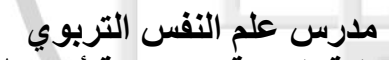

كلية التربية - جامعة أسيوط التفري

eman.elsherief@aun.edu.eg

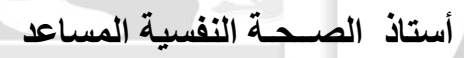
كلية التربية - جامعة أسيوط

Mostafaelhudaybi@aun.edu.eg

رشا عليوه أحمد عبد النبي

باحثة ماجستير في التربية الخاصة التئ تخصص (تخاطب)

كلية التربية - جامعة أسيوط

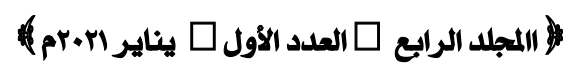

https://dapt.journals.ekb.eg

Your username is: ali_salah790@yahoo.com 


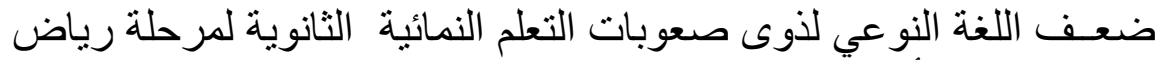

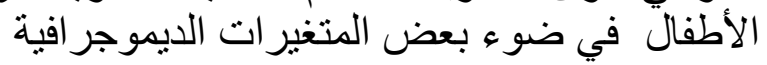

دإمصطفى عبد المحسن الحديبي د/إيمان صلاح الدين حسين الشريف أرشا عليوه أحمد عبد النبي

\section{Your password is: ztu6y8qupw}

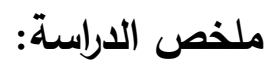

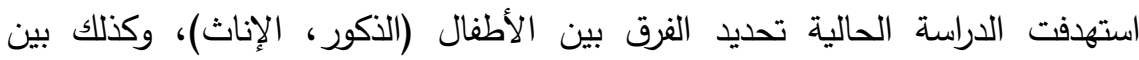

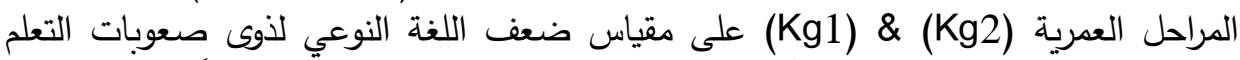

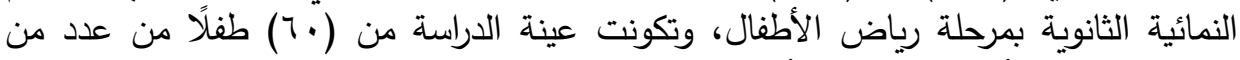

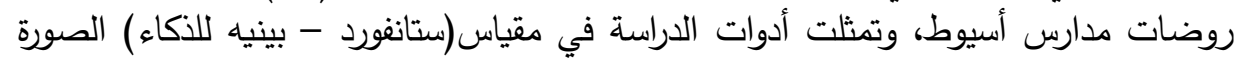

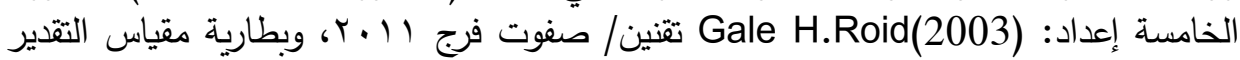

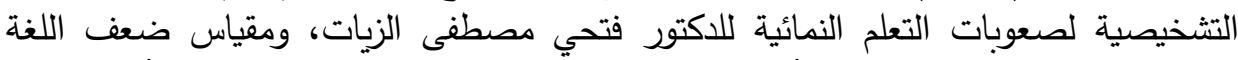

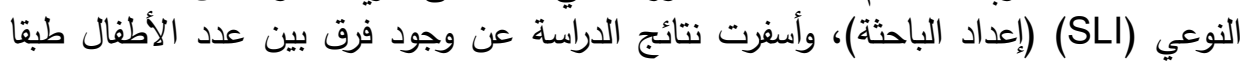

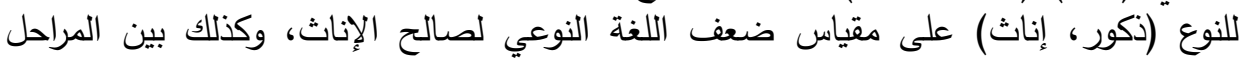

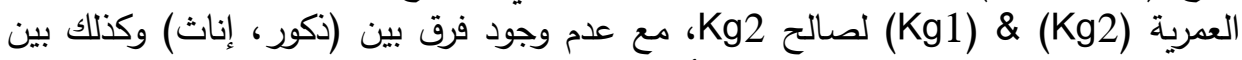
(KG2، و في نوع الضعف على (KG1)

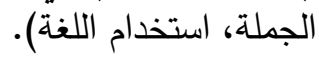

الكلمات المفتاحية: ضعف اللغة النوعي، صعوبات التعلم النمائية الثانوية . .

\section{Abstract :}

The current study aimed to determine the difference between children (males and females), as well as between the age stages (Kg1) \& $(\mathrm{Kg} 2)$ on the scale of specific language weakness for those with secondary developmental learning difficulties in kindergarten, and the study sample consisted of (60) children from a number of kindergartens Assiut schools, the study tools were represented in the (Stanford - Binet scale of intelligence) Fifth image prepared by: Gale H. Roy (2003) Taqnin / Safwat Farag 2011, the battery of the Diagnostic Assessment Scale for Developmental Learning Disabilities by Dr. Fathi Mostafa AlZayat, and the Specific Language Impairment Scale (SLI) (Preparation of the researcher), and the results of the study resulted in a difference between the number of children according to gender (males and females)on the scale of specific language impairment in favor of females, as well as between the age stages $(\mathrm{Kg} 1)$ \& $(\mathrm{Kg} 2)$ in favor of $\mathrm{Kg} 2$, with no difference between (males) Female)as well as between (KG1 and KG2) 
مجلة در اسات فى مجال الإرشاد النفسي و التربوي ـ كلية التربية ـ جامعة أسيوط

in the type of weakness on the scale dimensions, whether in (vocabulary recognition, sentence comprehension, language use).

Key words: specific language impairment, secondary developmental learning difficulties 


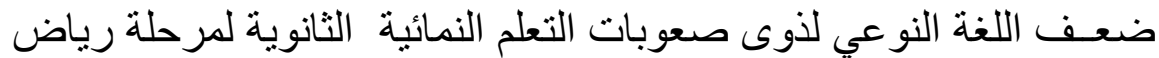
الأطفال في ضوء لأنو بعض المتغير ات الديموجر افية النية

دامصطفى عبد المحسن الحديبي د/إيمان صلاح الدين حسين الثريف أ/رشا عليوه أحمد عبد النبي

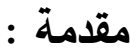

تعد عملية تعلم اللغة واكتساب المهارات المرتبطة بها هدفاً رئيساً من أهداف العملية

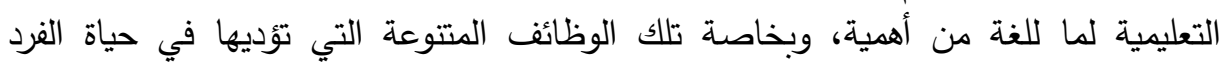

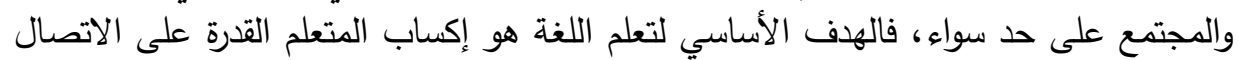

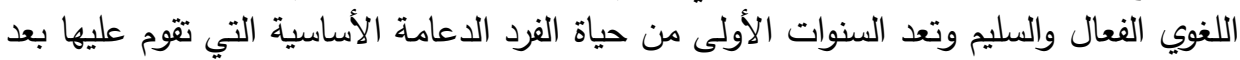

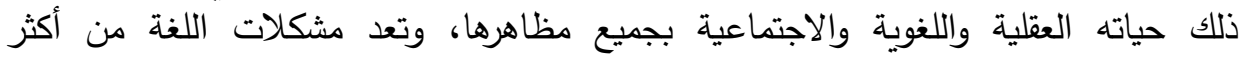

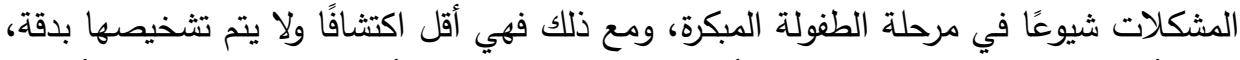

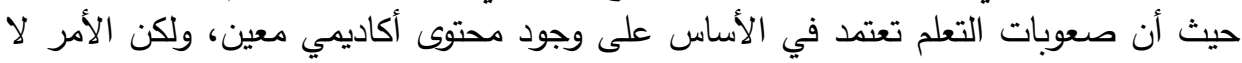

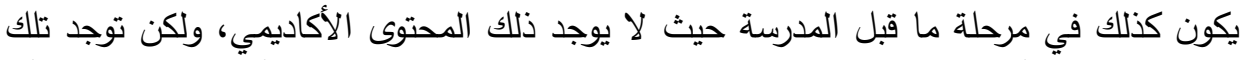

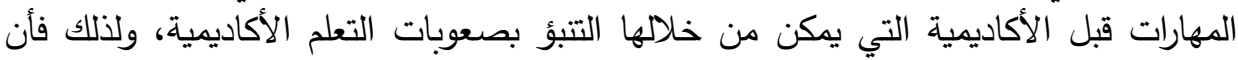

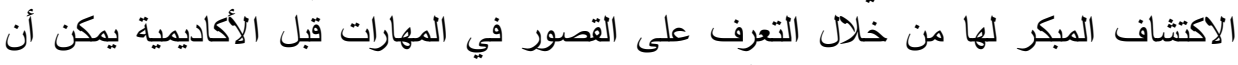

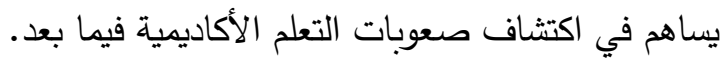

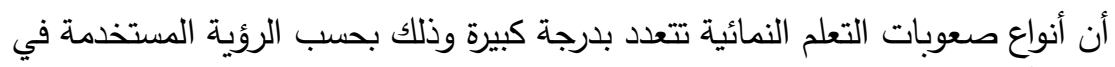

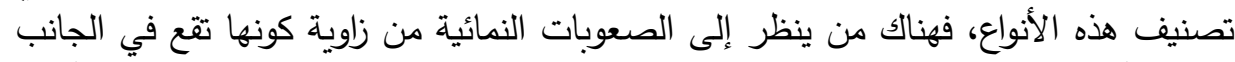

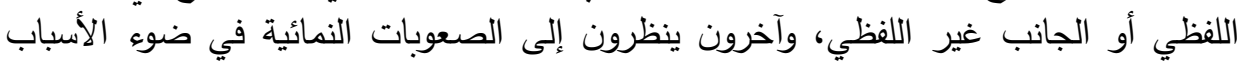

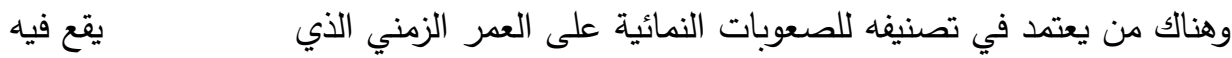

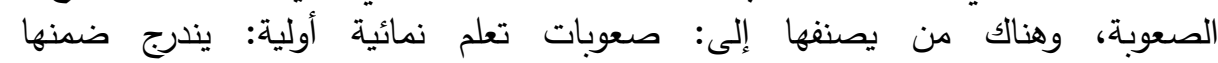

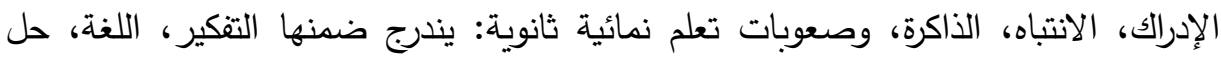

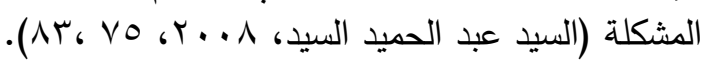

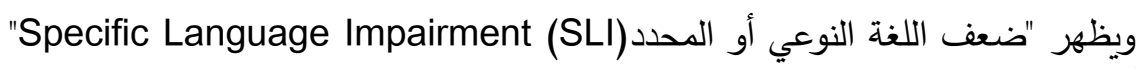

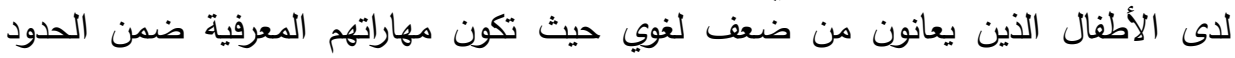

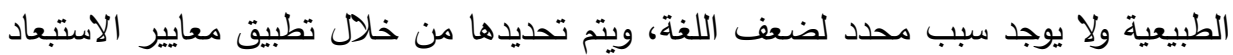
Henry et al., (2012, 37) (Reilly et al., 2014, 3)

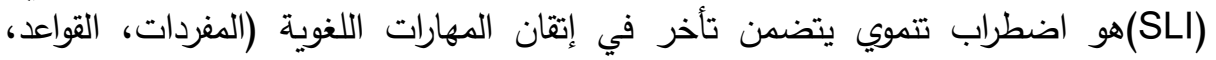

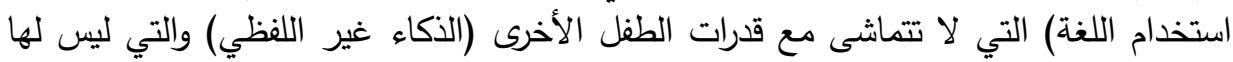

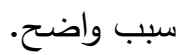

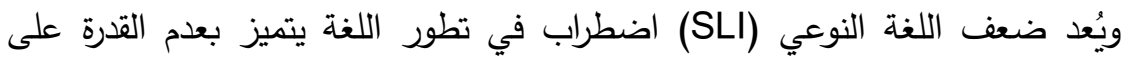
إتقان اللغة المنطوقة والمكتوبة والتعبير عن الفهم، على الرغم من الذكاء غير اللفظي العادي، لفعيل 
مجلة در اسات فى مجال الإرشاد النفسي و التربوي ـ كلية التربية ـ جامعة أسيوط

وحدّة السمع، والمهارات الحركية للكلام، وعدم وجود إعاقة جسدية أو متلازمة معترف بها

.(Evans \& Brown, 2016, 899)

وتُظهر نتائج دراسة (Thordardottir et al ., (2002, 245) أن هناك علامات

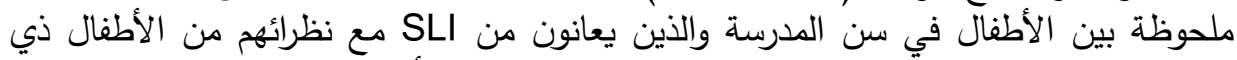

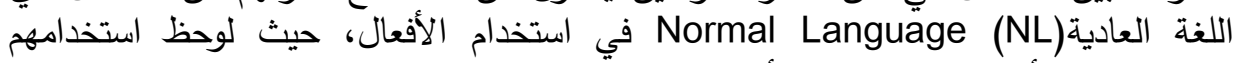

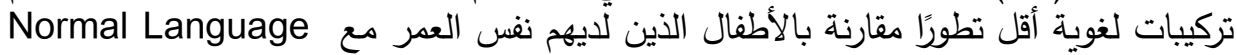

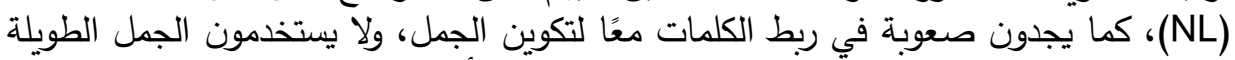

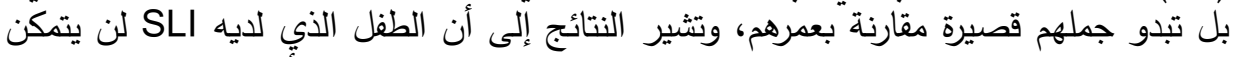

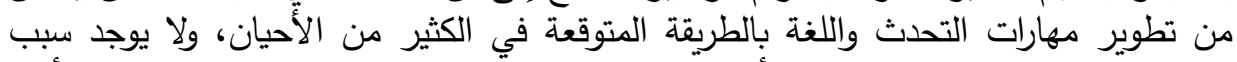

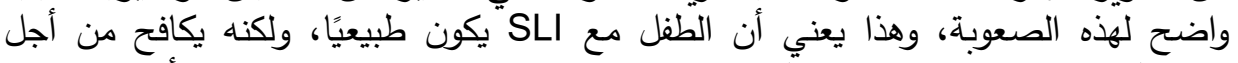

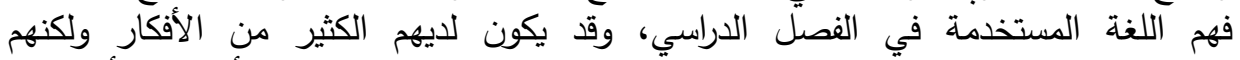

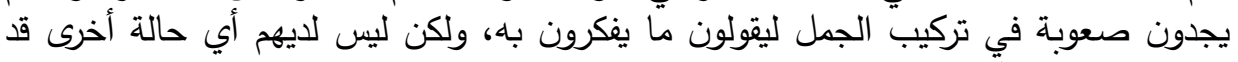

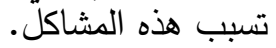

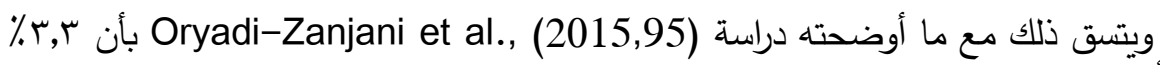

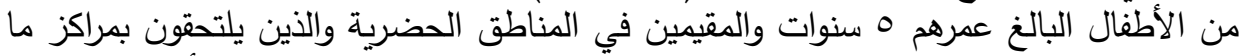

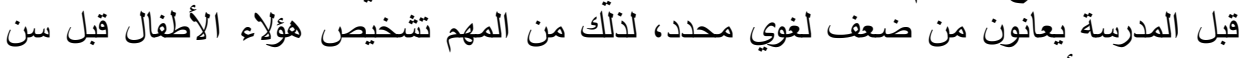
المدرسة من أجل علاجهم للوقاية من المشاكل اللاحقة.

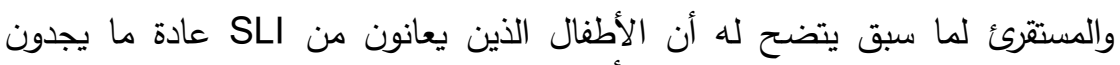

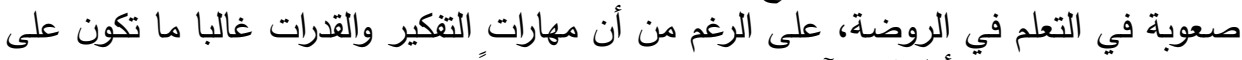

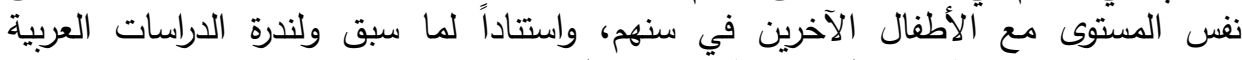

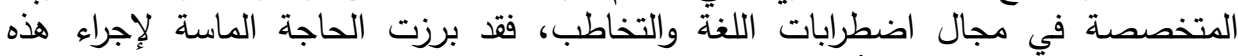

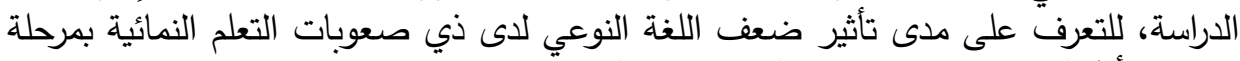

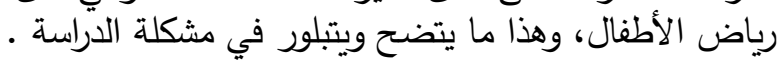

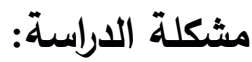

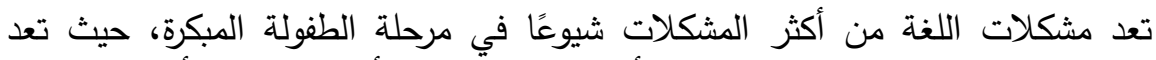

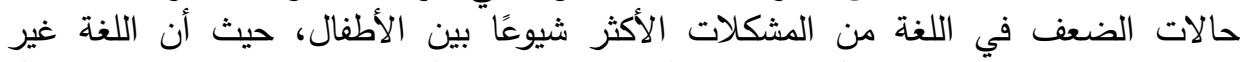

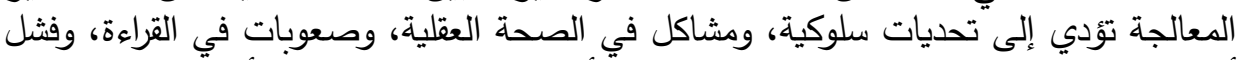

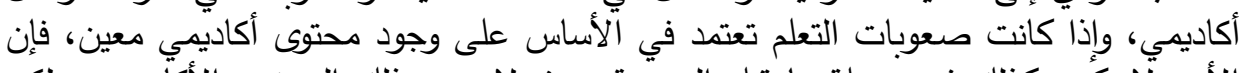

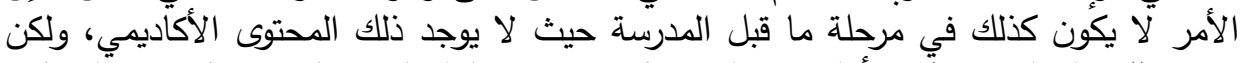

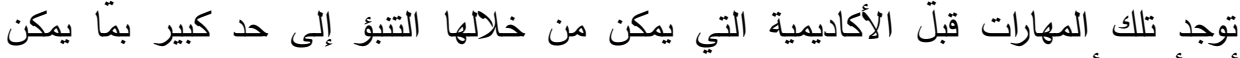

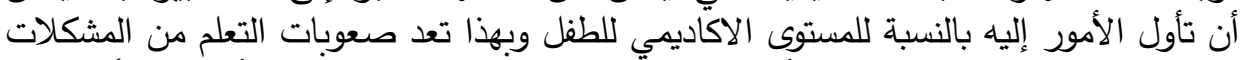

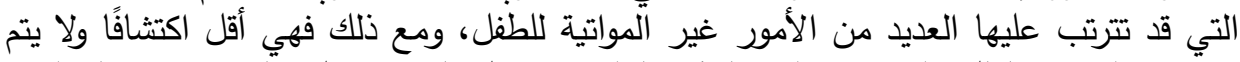
تثخيصها بدقة، لذلك فإن الاكتشاف المبكر لها من خلال التعرف على الته ألقصور في المهارات 


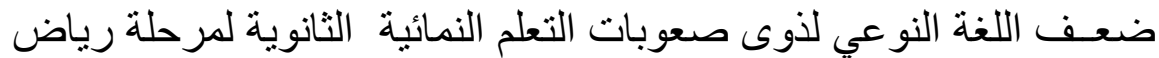

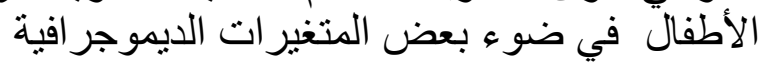

دامصطفى عبد المحسن الحديبي د/إيمان صلاح الدين حسين الثريف أ/رشا عليوه أحمد عبد النبي

قبل الأكاديمية التي يمكن أن تساهم في حدوثها من شأنه أن يحد كثيرًا من تأثيرها السيئ

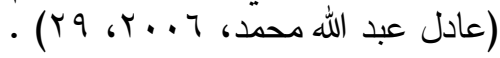

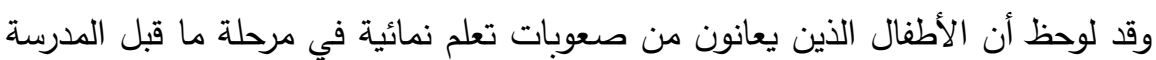

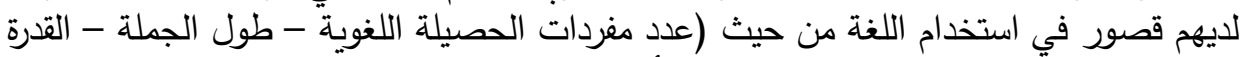

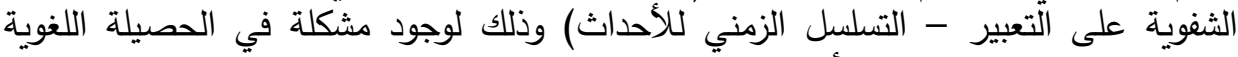

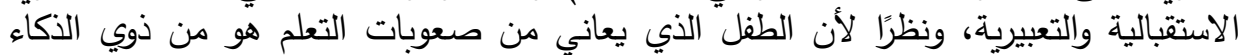

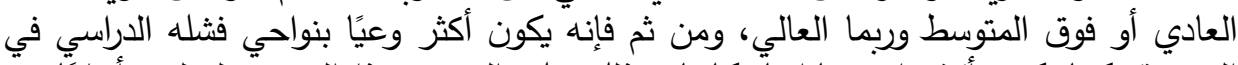

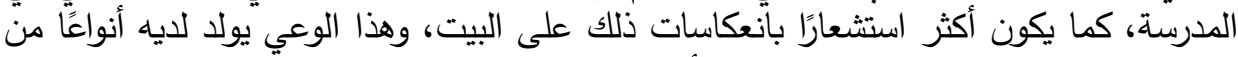

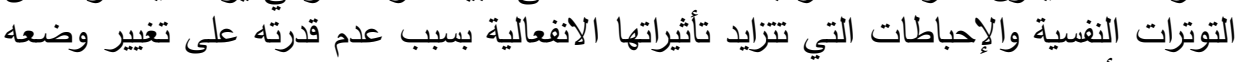

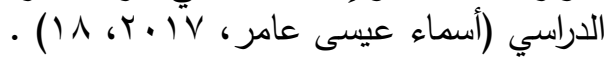

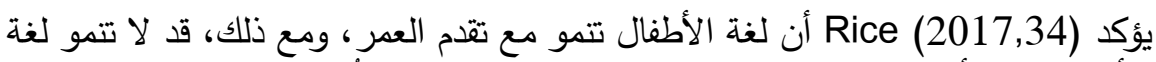

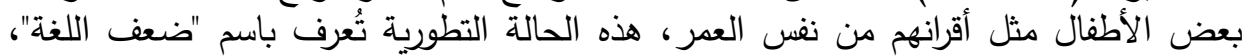

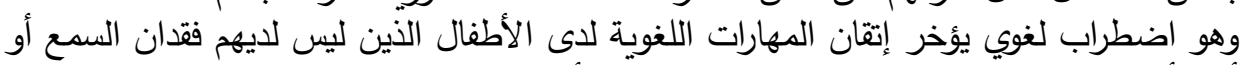

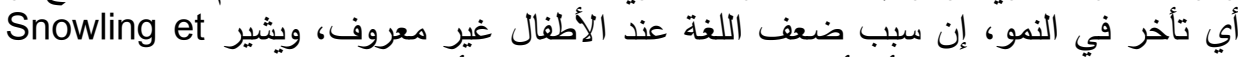

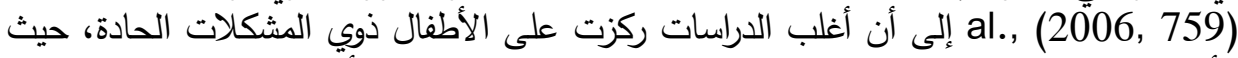

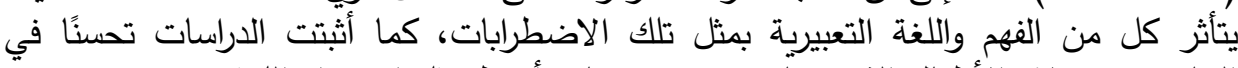

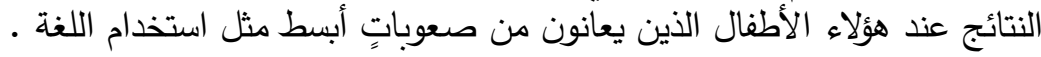

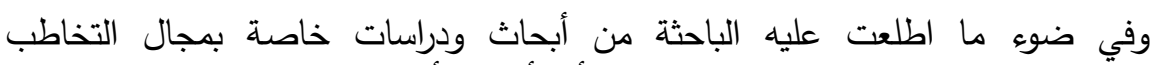

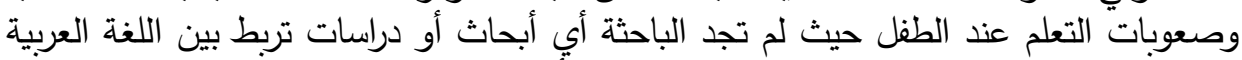

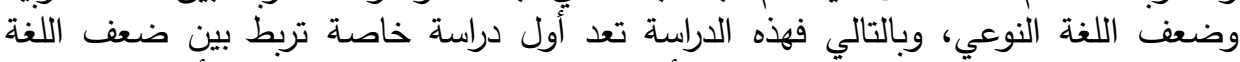

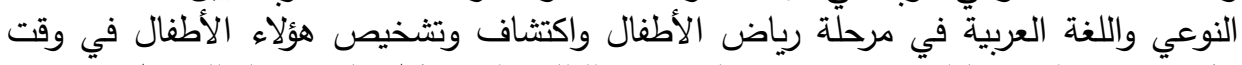

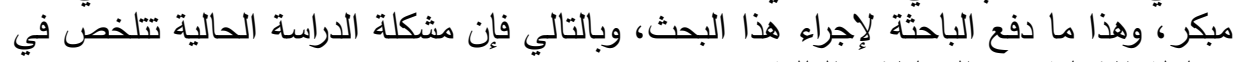
محاولة الإجابة عن التساؤلات التالية: الإهاء

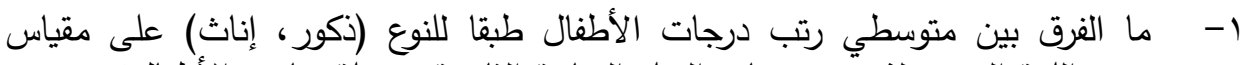

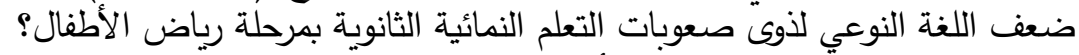

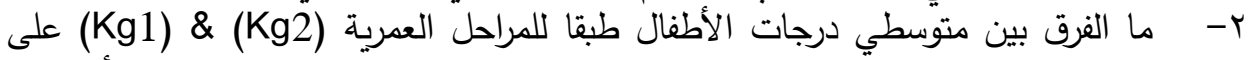

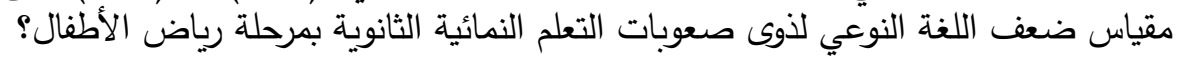

\section{أهدف الاراسة : هدفت الدراسة الحالية إلى التعرف على :}

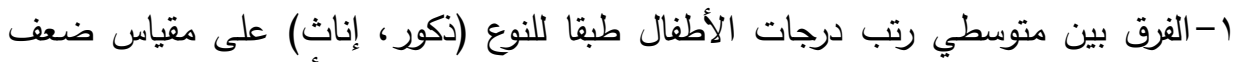

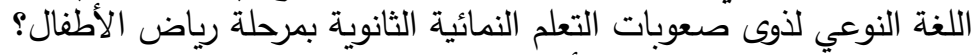

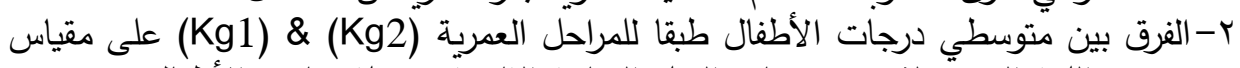
ضعف اللغة النوعي لذوى صعوبات التعلم النمائية الثانوية بمرحلة رياض الألية الأطفال؟ 
مجلة در اسات فى مجال الإرشاد النفسي و التربوي ـ كلية التربية ـ جامعة أسيوط

\section{أهمية الدراسة :}

تتضح أهمية الدراسة الحالية من خلال ما يلى :

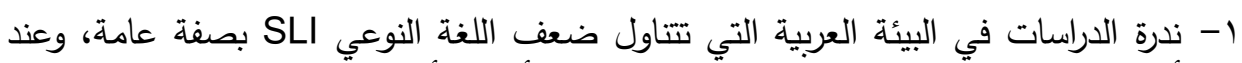

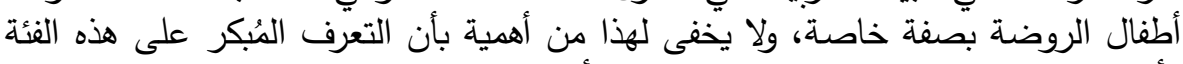

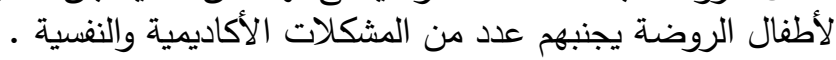

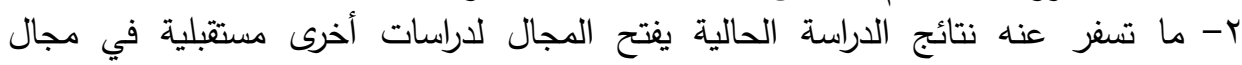

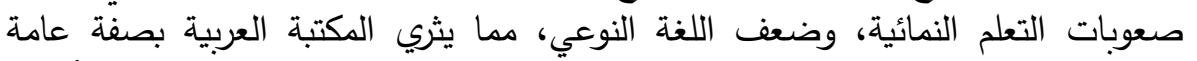
ومجال التربية الخاصة بدراسات تتصف بالجدة حول ضعف النعف اللغة النوعي (SLI) لأطفال الروضة.

r- الاكتثاف المبكر للأطفال الذين يعانون من ضعف اللغة النوعي (SLI) في مرحلة رياض لإلفال

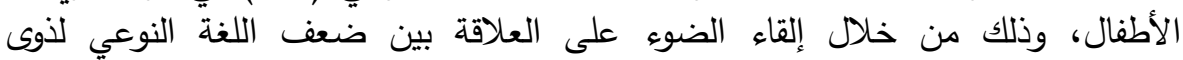

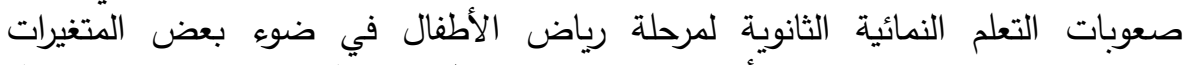

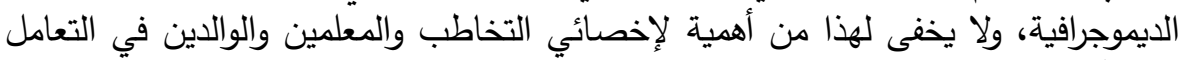
مع الأطفال الذين يعانون من ضعف لألف اللغة النوعي.

الإطار النظري والمفاهيم الإجرائية للدراسة :

-

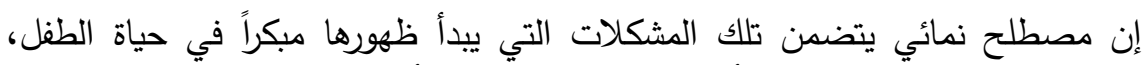

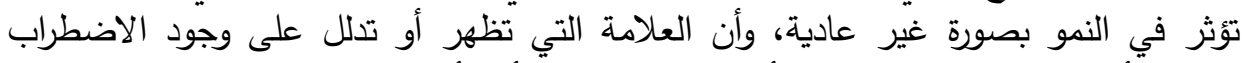

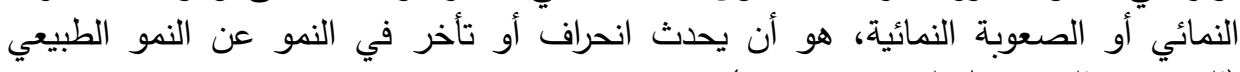

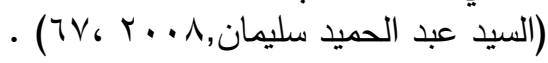

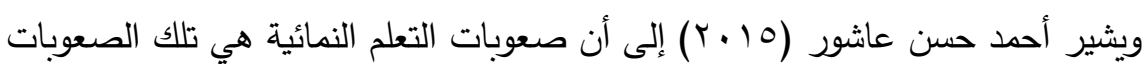

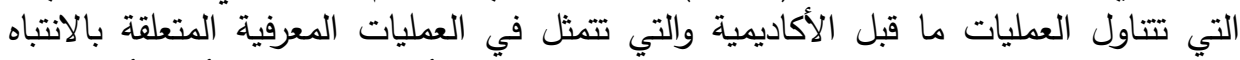

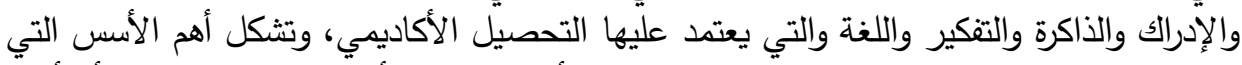

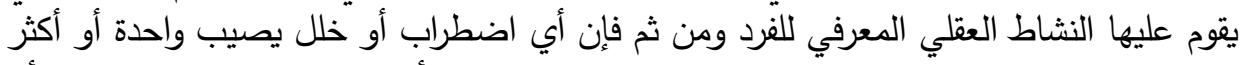

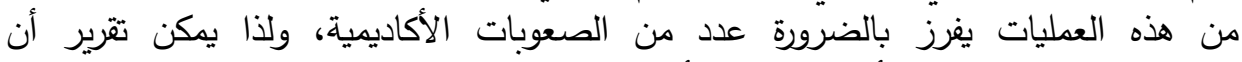

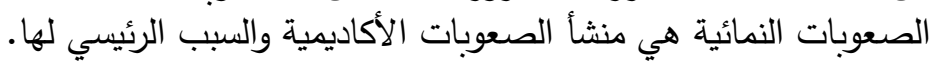

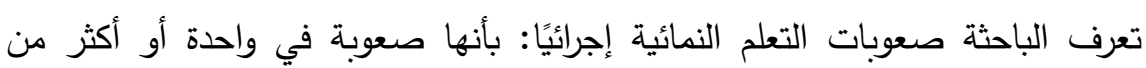

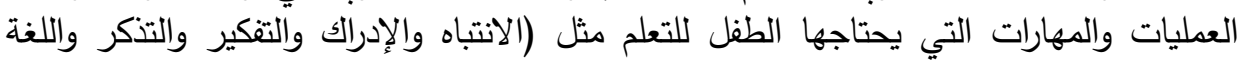

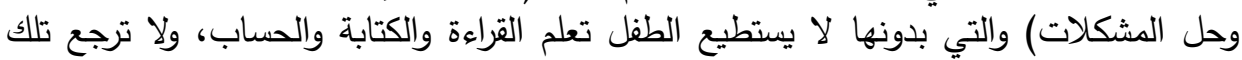

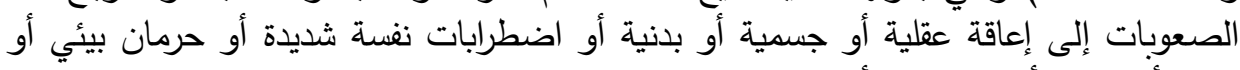
ثقافي أوتعليمي أو اقتصادي أواجتماعي. 


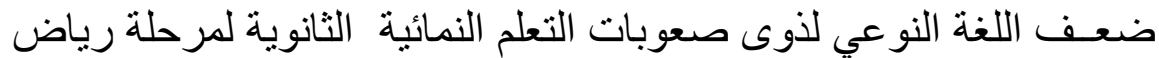

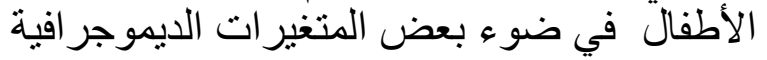

دامصطفى عبد المحسن الحديبي د/إيمان صلاح الدين حسين الثريف أ/رشا عليوه أحمد عبد النبي

إن صعوبات تعلم اللغة تثير إلى انخفاض دال وملموس في النظام اللغوي لدى الفرد

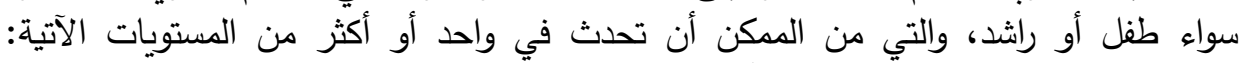

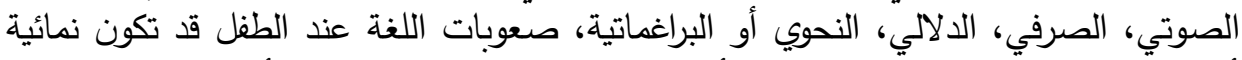

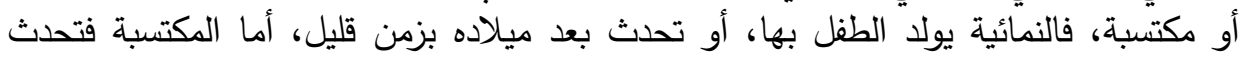

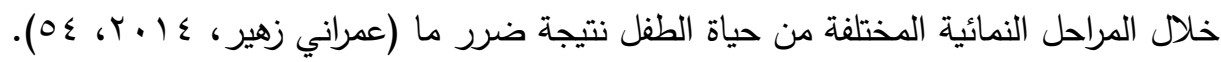

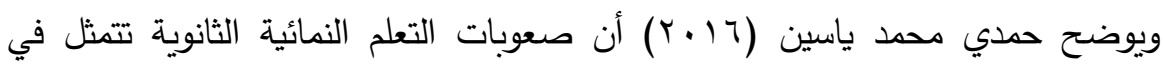

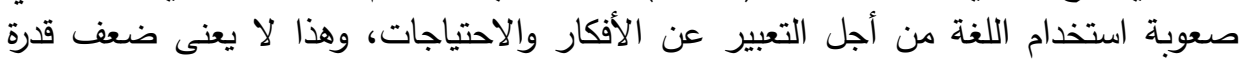

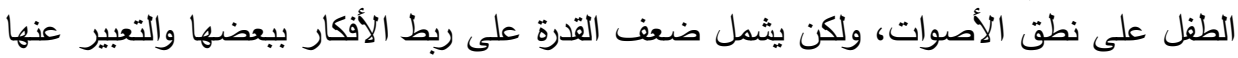

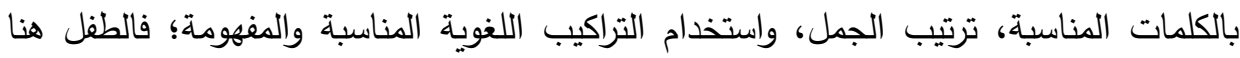

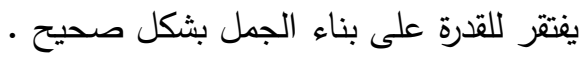

وتُعرف الباحثة صعوبات التعلم النمائية الثانوية: بأنها تلك المهارات التي يحتاجها الطفل

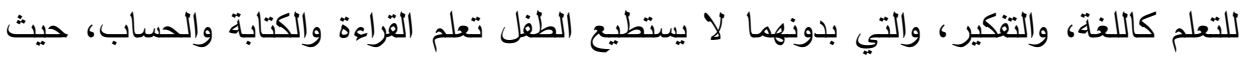

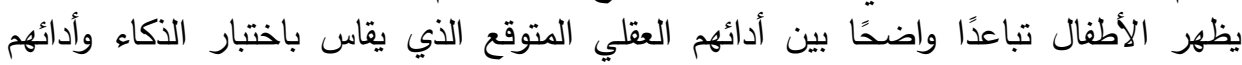

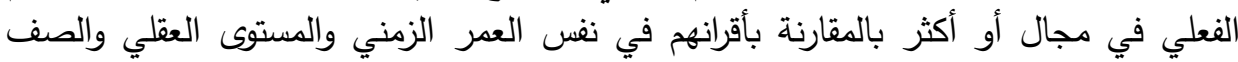

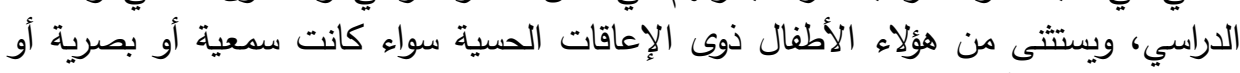
حركية وكذلك المتأخرين عقليًا والمضطربين النفعاليًا والمحرومين ثقافيًا واقتصاديًا.

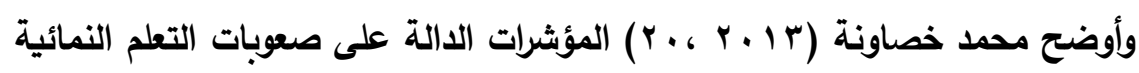
الثانوية في : أن

1- اضطرابات في التفكير : كمشكلات في العمليات العقلية، كالحكم، والمقارنة، وإجراء العمليات

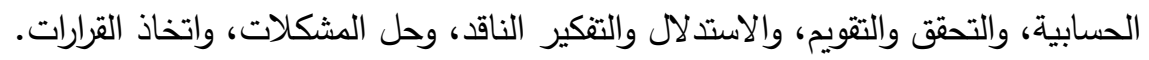

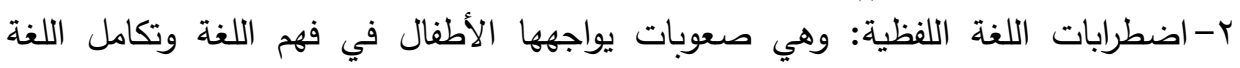
الداخلية والتعبير عن الأفكار لفظيًا.

هناك إشارات وعلامات تساعدنا على التعرف على وجود اضطرابات لغوية لاى التى

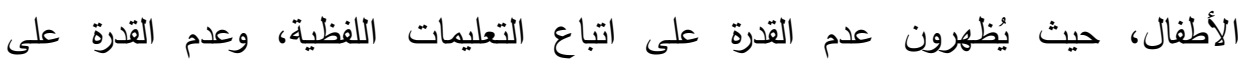

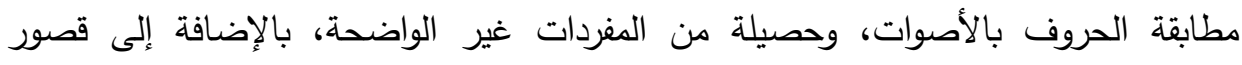

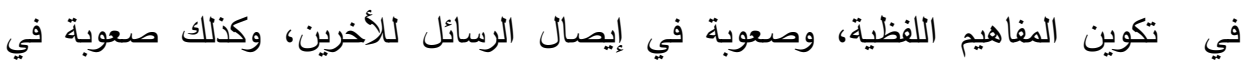

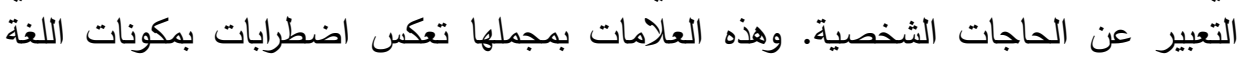

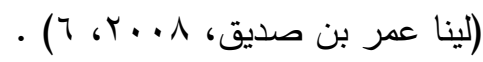


مجلة در اسات فى مجال الإرشاد النفسي و التربوي ـ كلية التربية ـ جامعة أسيوط

: Specific Language Impairment (SLI) بع - أبعف اللغة النوعي أ- تعريف ضعف اللغة النيّ النوعي ونسبة انتشاره :

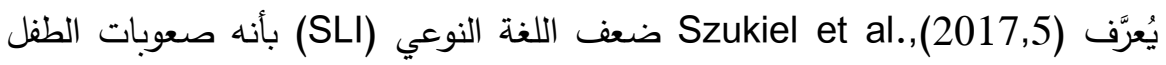

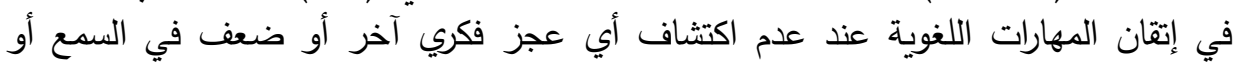

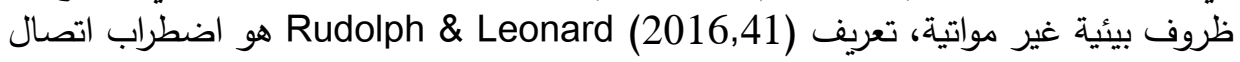

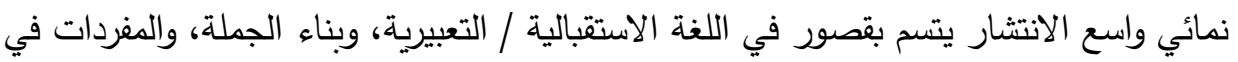

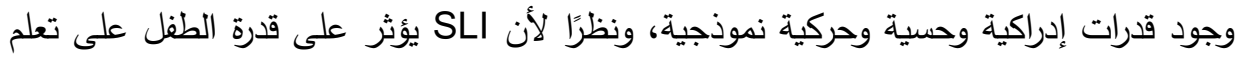

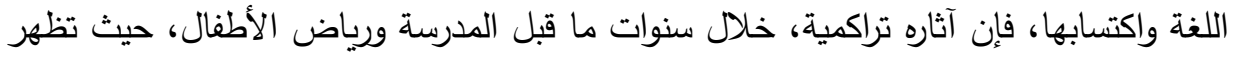

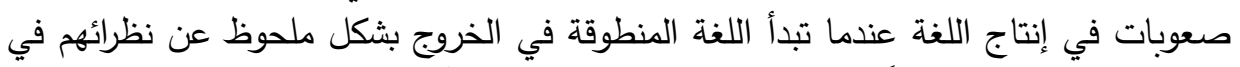

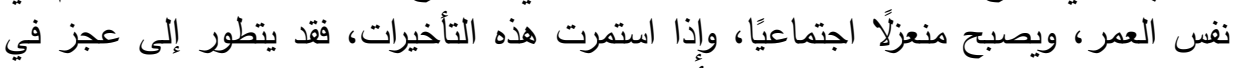

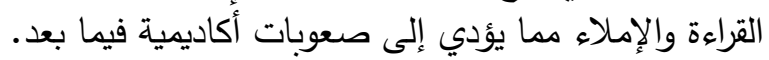

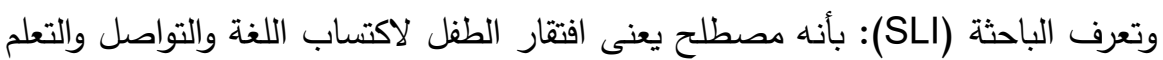

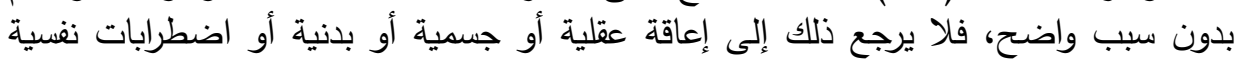

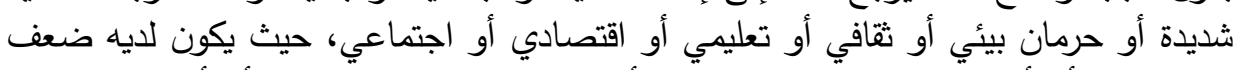

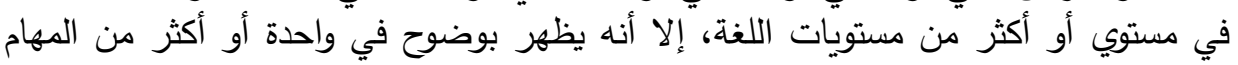

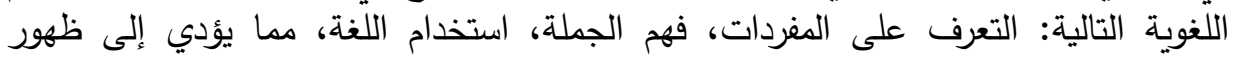
صعوبات التعلم النمائية لاى الطفل.

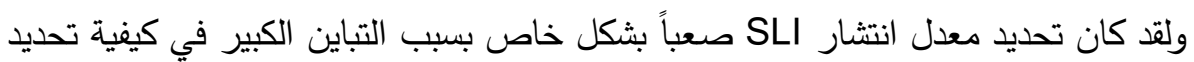

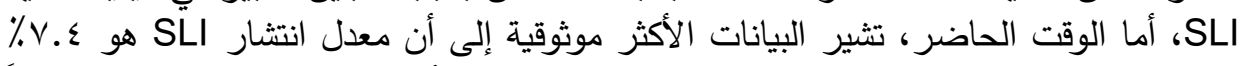

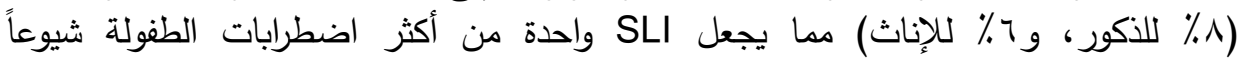
. (Prelock \& Hutchins, 2018, 58)

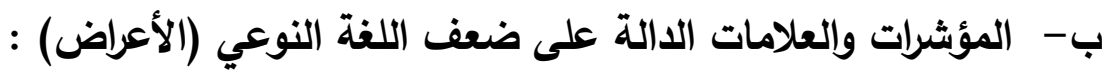

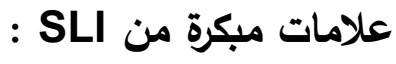

الأطفال الصغار الذين يعانون من SLI لديهم مهارات وقدرات مثل أقرانهم لكنهم سوف

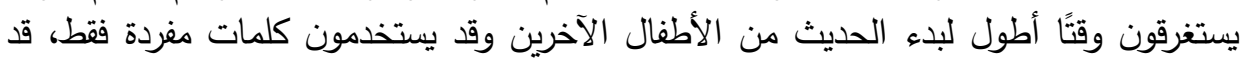

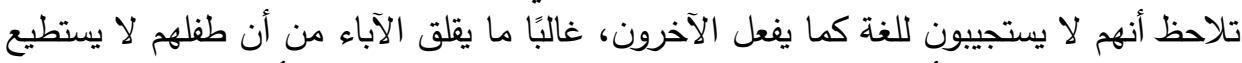

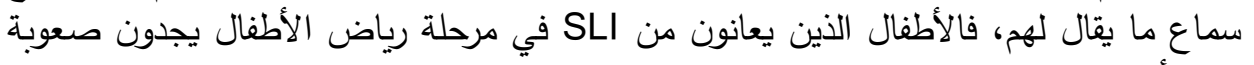
في الأمور التالية :

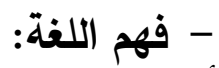

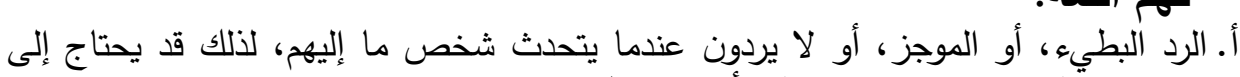

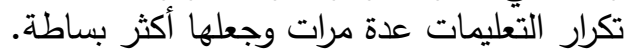
ب. غالبًا ما يعتمدون على المعلومات المرئية،على سبيلى بلى الميل المثال،مشاهدة الآخرين لمعرفة ما تعنيه. 


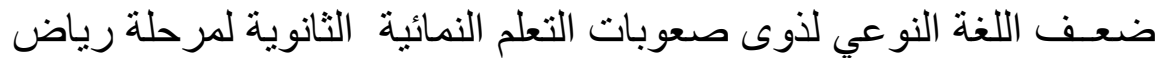

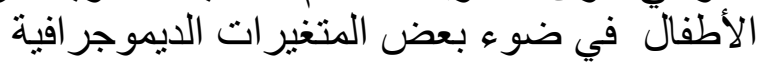

دامصطفى عبد المحسن الحديبي د/إيمان صلاح الدين حسين الثريف أ/رشا عليوه أحمد عبد النبي

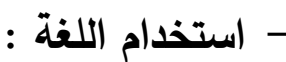

أ. قد لا يستخدمون العديد من الكلمات المختلفة. ب. ال يجدون صعوبة في ربط الكلمات معًا لتكوين جملة.

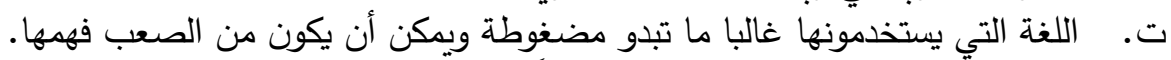

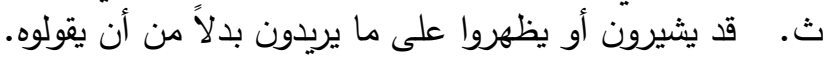

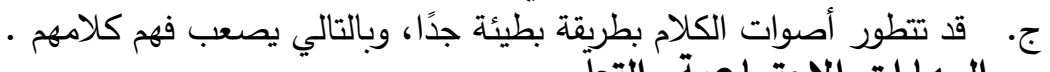

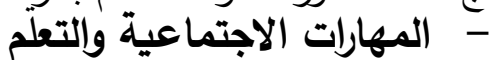

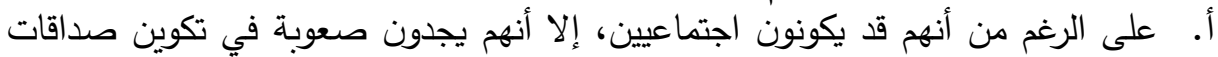

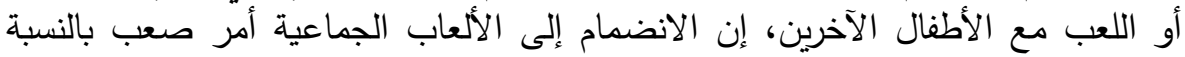

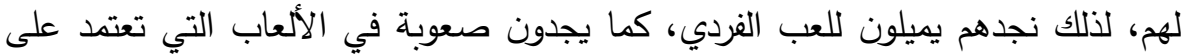

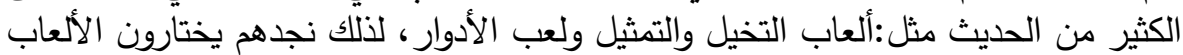

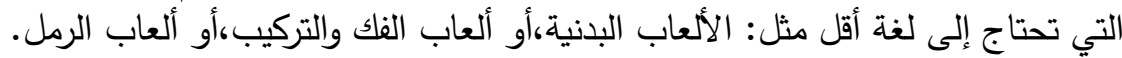

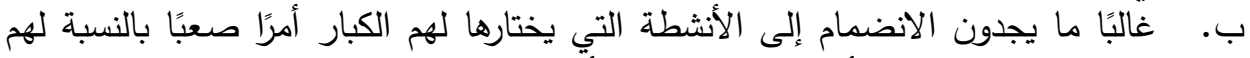

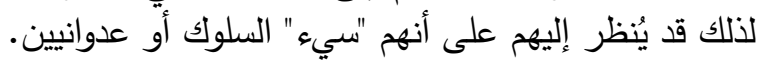

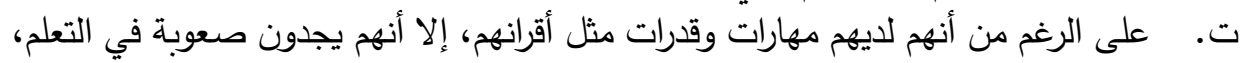

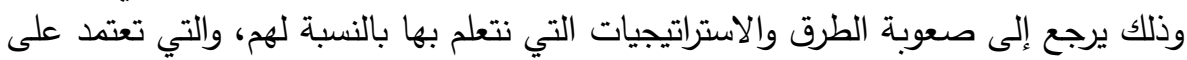

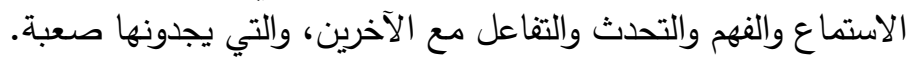

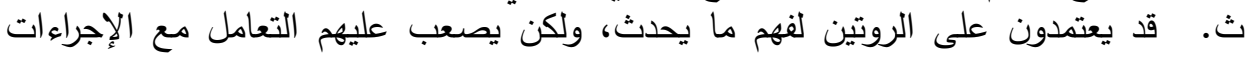

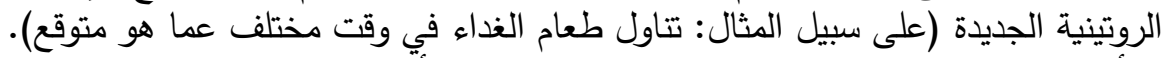

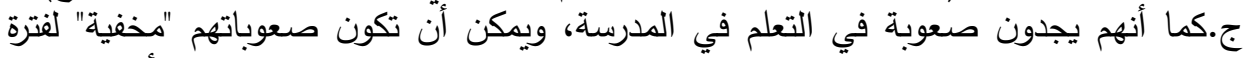

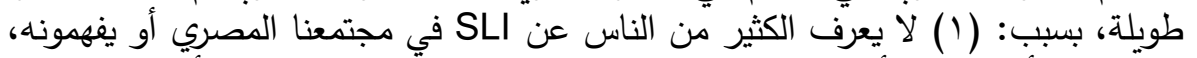

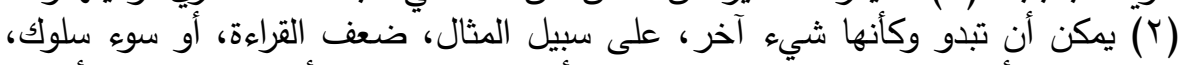

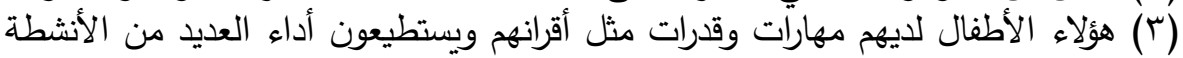

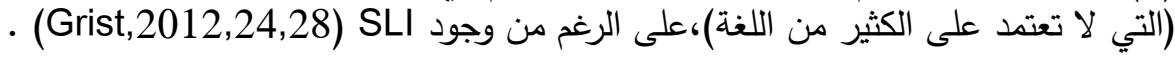

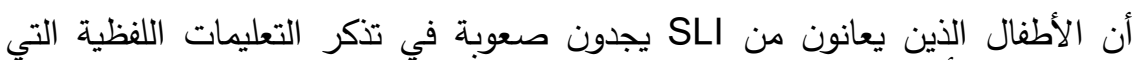

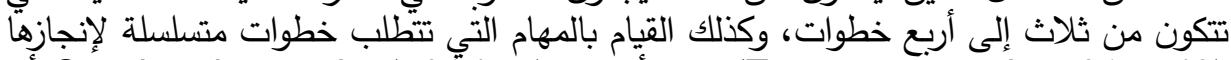

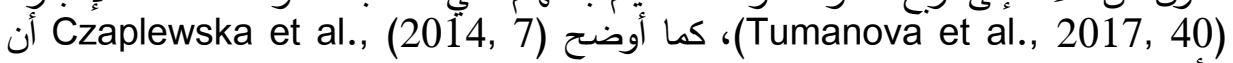
الأطفال الذين يعانون من

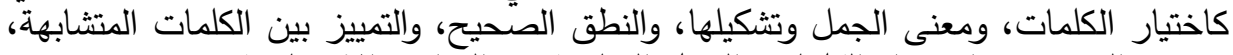

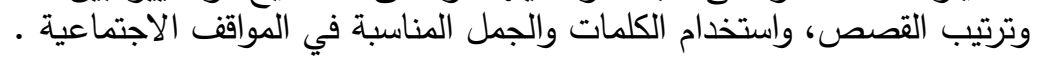

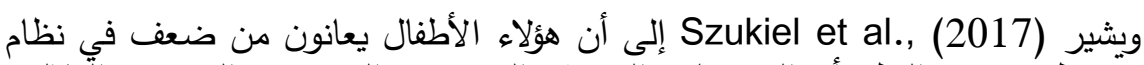
اللغة، قد تغطي جميع النظم أو المستويات الفرعية: الصوتي، والصرفي، والصغانون والنحوي، والّدلالي، 
مجلة در اسات فى مجال الإرشاد النفسي و التربوي ـ كلية التربية ـ جامعة أسيوط

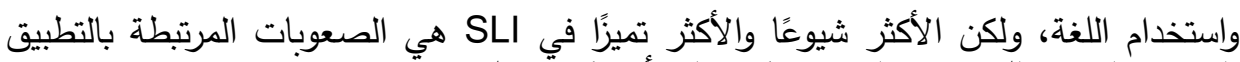

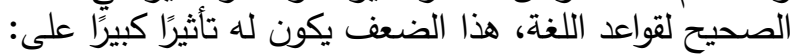

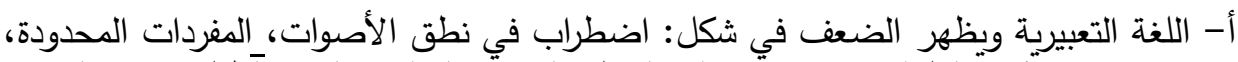

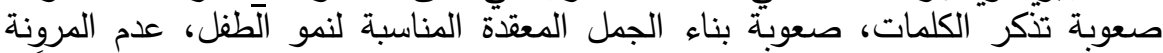

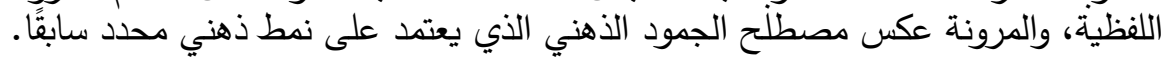

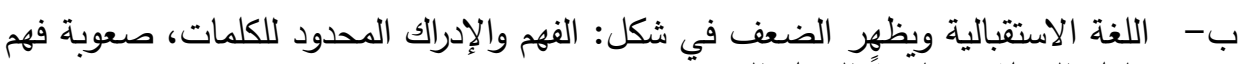
هياكل الجملة، وخاصَّةً الجمل المعقدة.

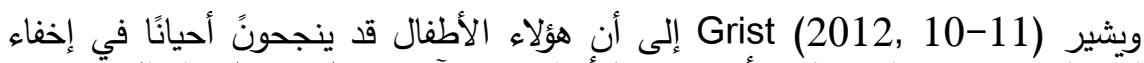

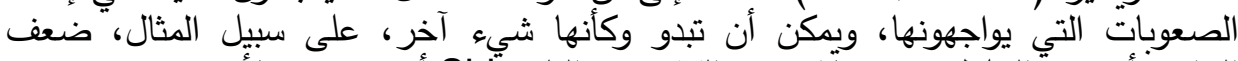

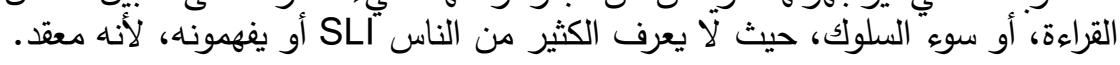

\section{ج- تشخيص SLI لأطفال ما قبل المدرسة:}

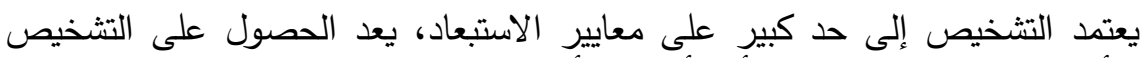

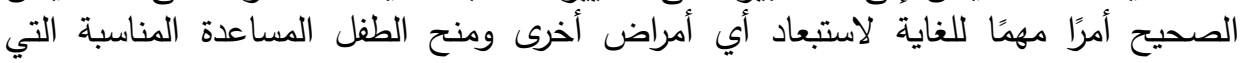

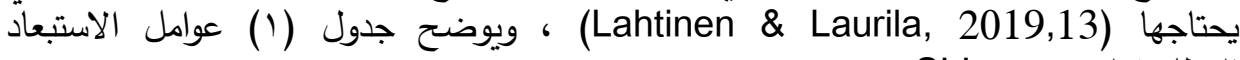

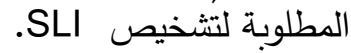

جدول (1)

SLI عوامل الاستبعاد المطلوبة لتشخيص

\begin{tabular}{|c|c|c|}
\hline 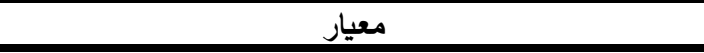 & عامل استبعاد & م \\
\hline 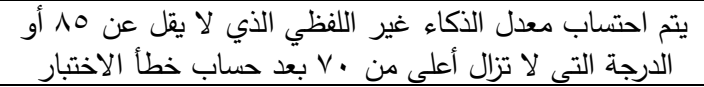 & الذكاء غير اللفظي & 1 \\
\hline لا يوجد مؤشر على ضعف المستوع ، يتم تطبيق اختبارات السمع & 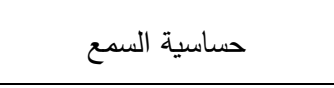 & $r$ \\
\hline 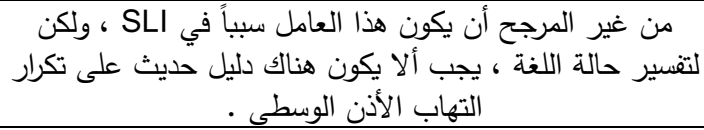 & التهاب الأذن الوسطى المتكرر & $r$ \\
\hline لا تشوهات هيكلية أو وظيفية & هيكل الفم وسلامته الوظيفة & $\varepsilon$ \\
\hline لا توجد أعراض لضعف التفاعل الاجتماعي المتبادل أو ممارسة & التفاعل مع الناس والكائنات & 0 \\
\hline لا يوجد دليل على الاضطراب العصبى . & وظيفة عصبية & 7 \\
\hline
\end{tabular}

والجدير بالذكر أن معظم الأطفال الذين يعانون من SLI يظهرون مكاسب في القدرة اللغوية

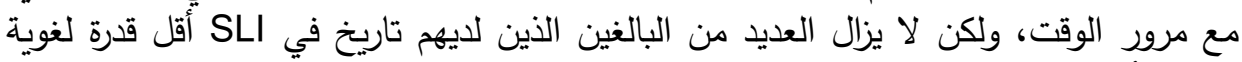

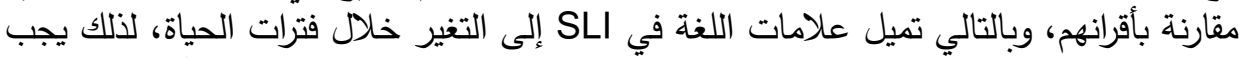
الاكتثاف المبكر ل SLI في مرحلة الطفولة المبكرة حيث تكون المشاكل اللغوية أكثر وضوحًا.

الاراسات ذات الصلة : الاستاف ل

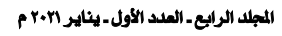

https://dapt.journals.ekb.eg

أولاً : دراسات تناولت صعوبات الهلة : التعلم النمائية

$1 \cdot 1$ 


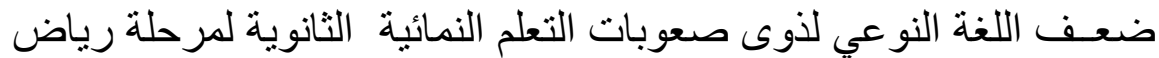

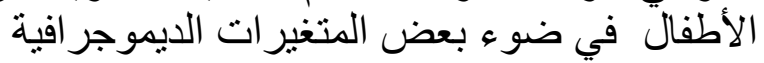

دامصطفى عبد المحسن الحديبي د/إيمان صلاح الدين حسين الشريف أرشا عليوه أحمد عبد النبي

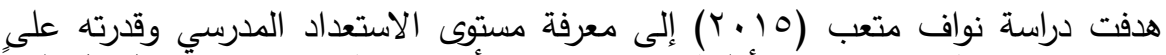

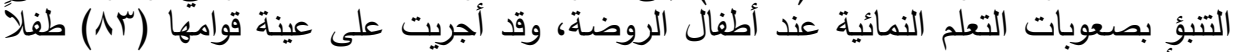

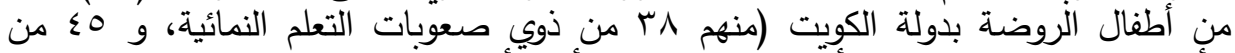

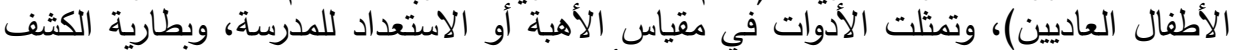

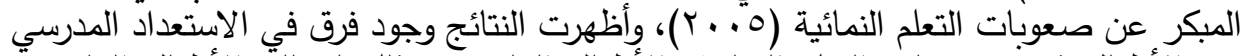

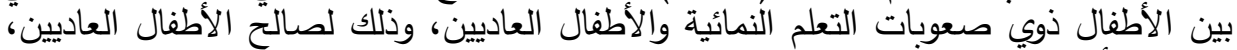

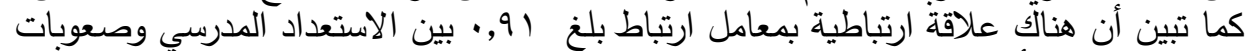

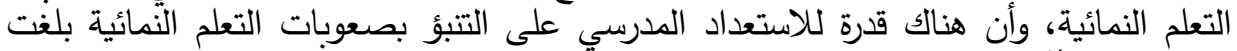

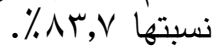

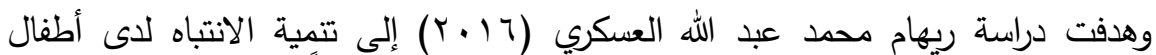

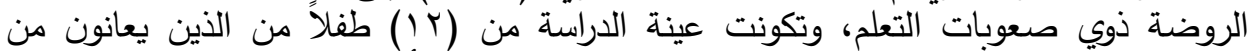

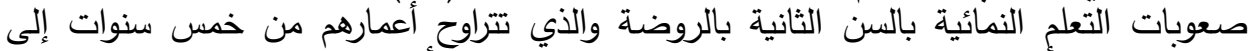

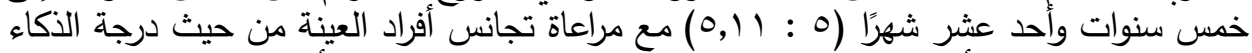

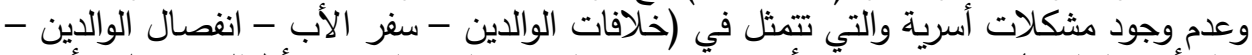

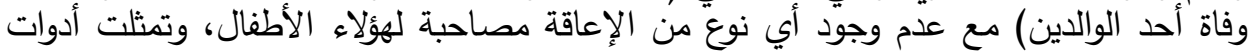

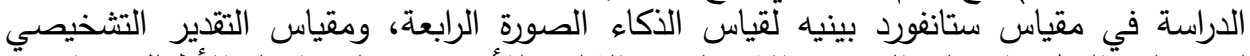

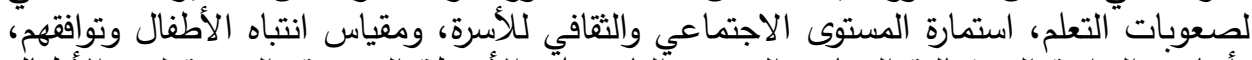

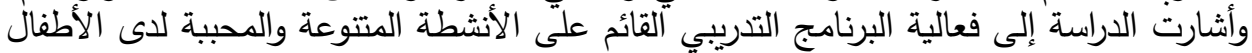

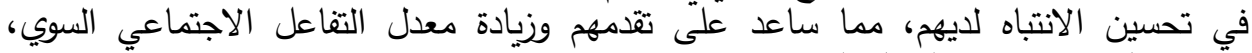
وأستمر التحسن بعد انتهاء البرنامج.

\section{ثانياً : دراسات تناولت ضعف لتهف اللغة النوعي}

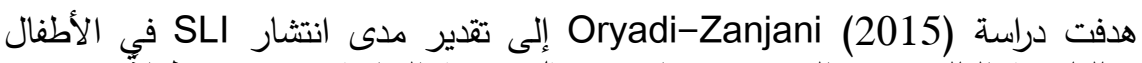

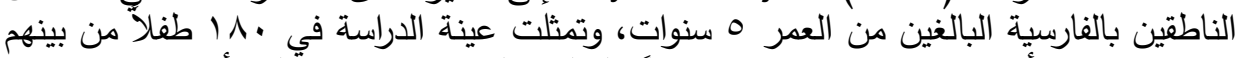

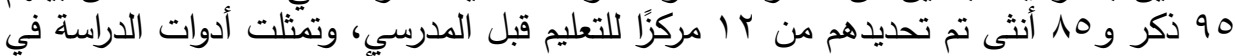

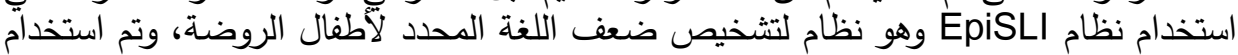
الإصدار الفارسي من اختبار تطوير اللغة (TOLD-P: 3) لتقييم مهارات اللغة التطورية

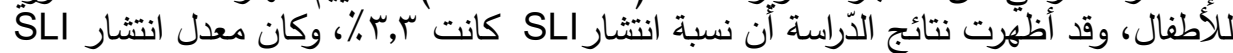

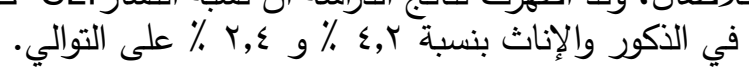

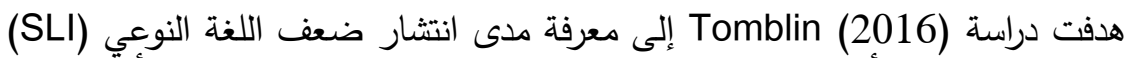

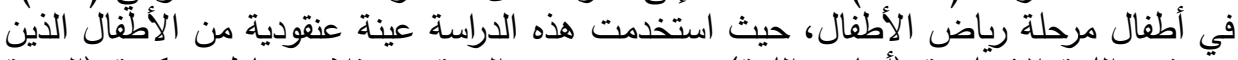

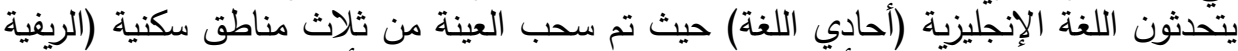

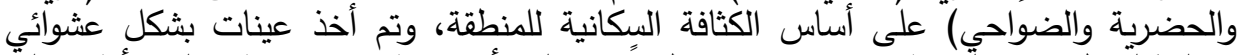

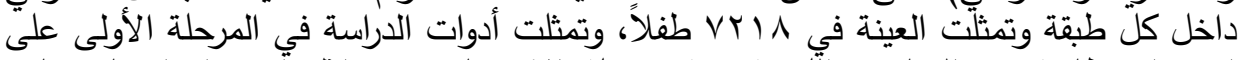

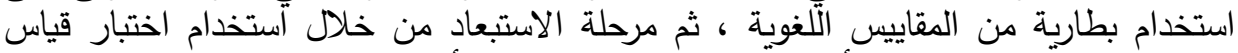

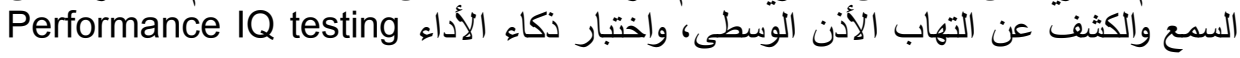


مجلة در اسات فى مجال الإرشاد النفسي و التربوي ـ كلية التربية ـ جامعة أسيوط

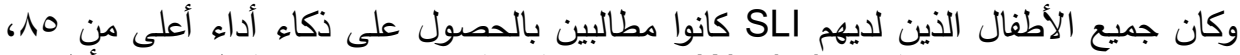

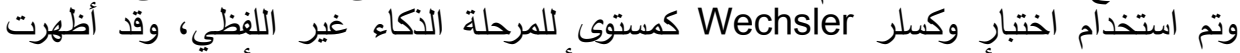

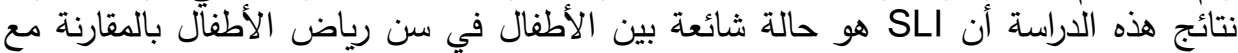

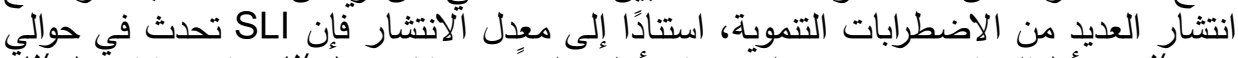

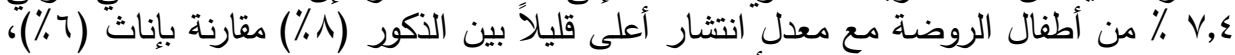

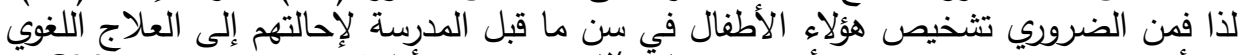

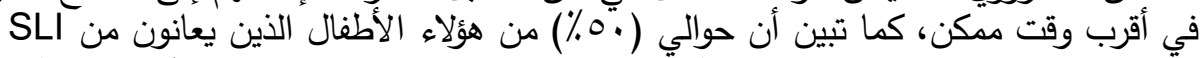

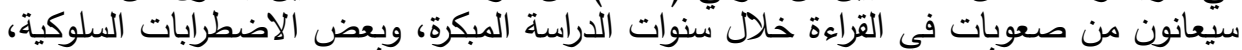

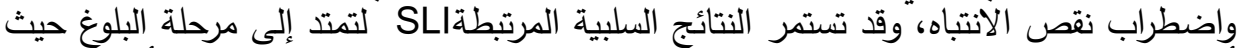

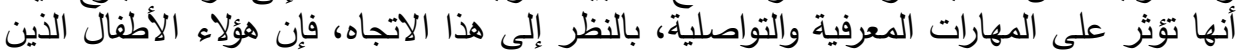

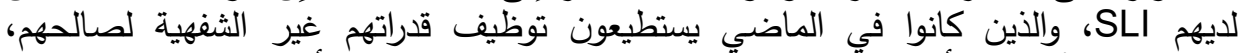

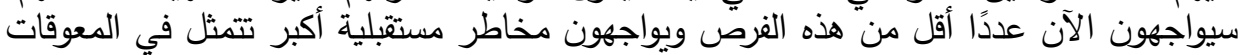

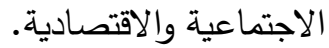

هدفت دراسة (2017) Ghayoumi إلى تقييم الخصائص النحوية للأطفال الذين

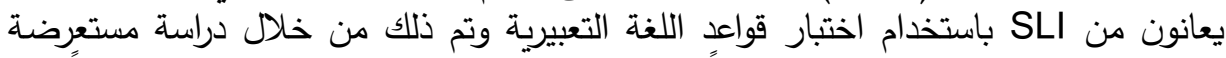

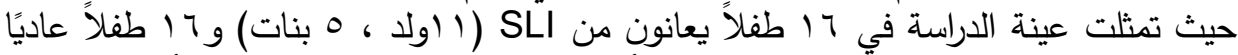

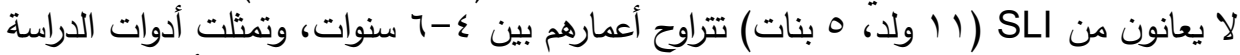

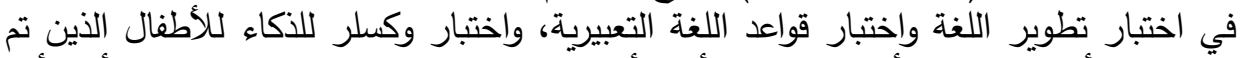

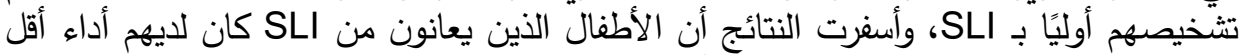

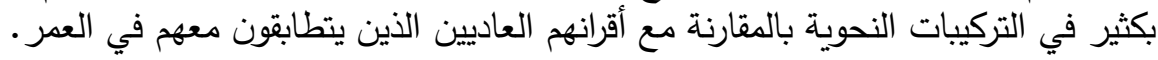

\section{تعقيب على الاراسات ذات الصلة : الصئة}

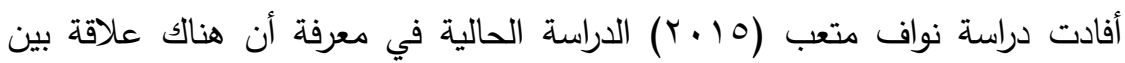

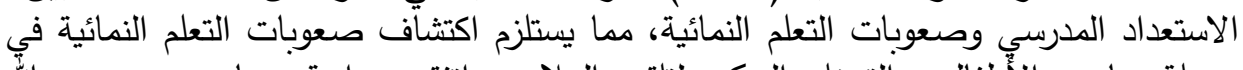

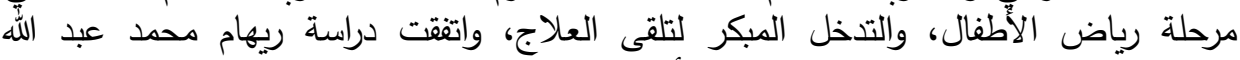

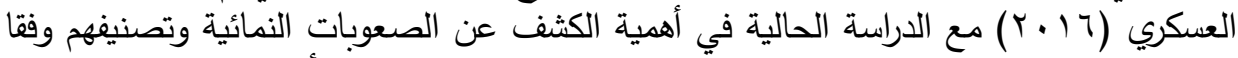

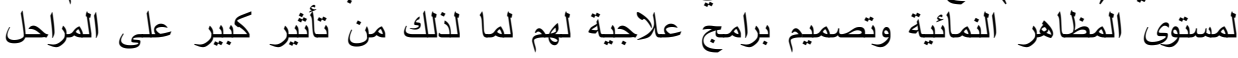

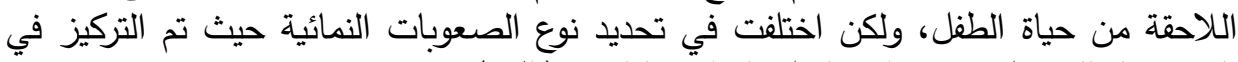

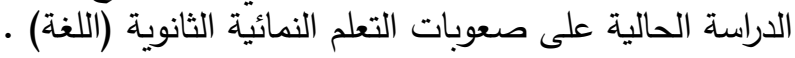

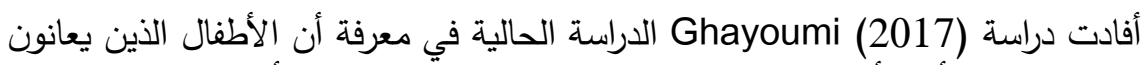

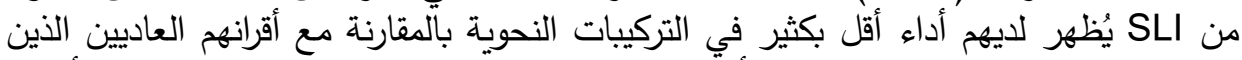

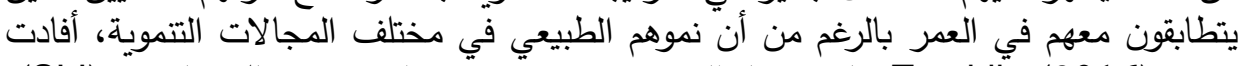

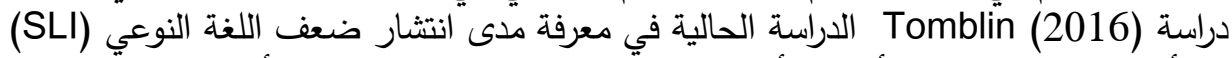

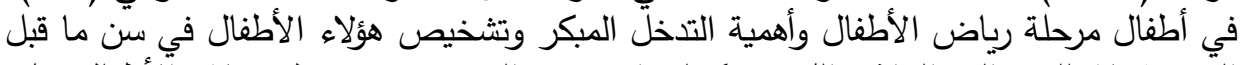

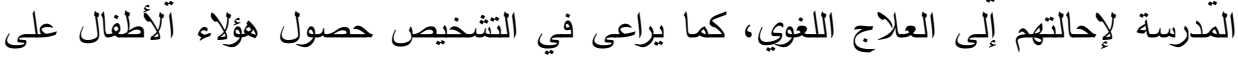

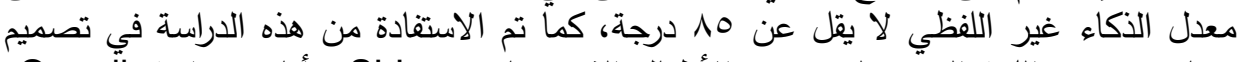

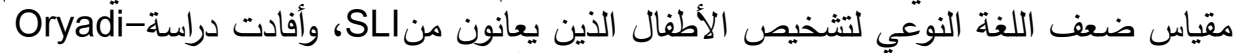

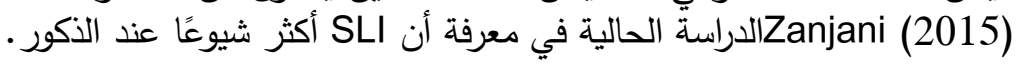




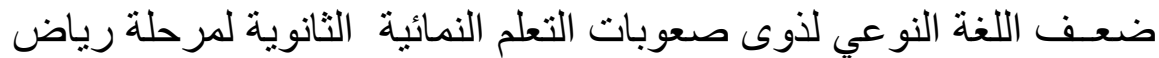

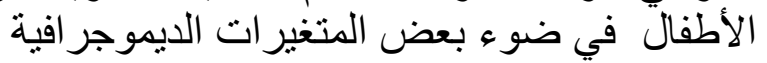

دامصطفى عبد المحسن الحديبي د/إيمان صلاح الدين حسين الثريف أ/رشا عليوه أحمد عبد النبي

\section{منهج وإجراءات الدراسة :}

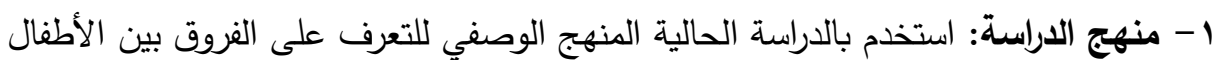

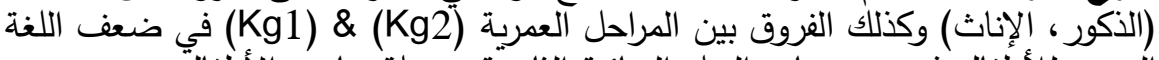

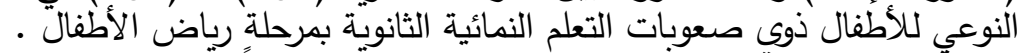

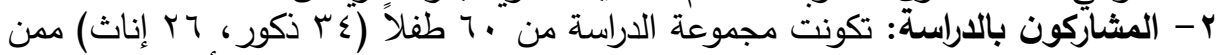

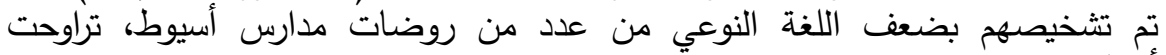

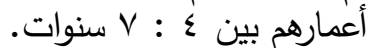

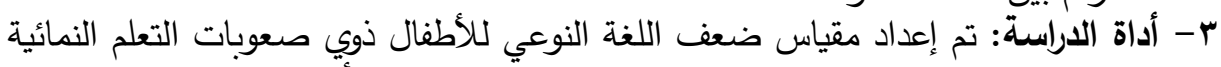

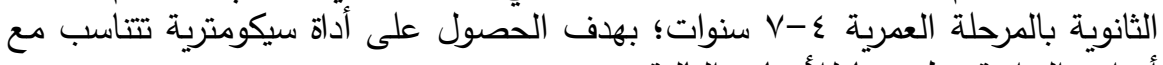
أهداف الدراسة وطبيعتها للأسباب التالية:

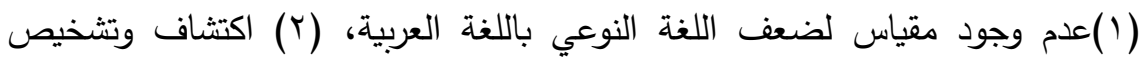

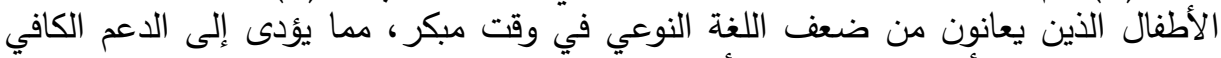

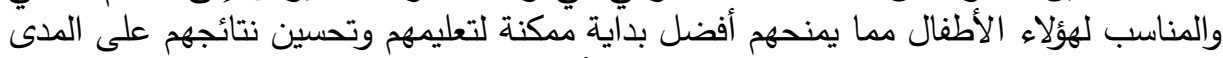

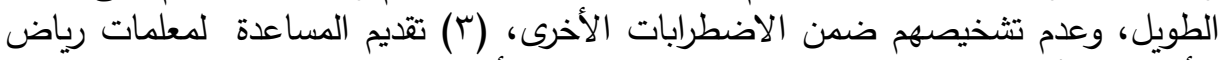

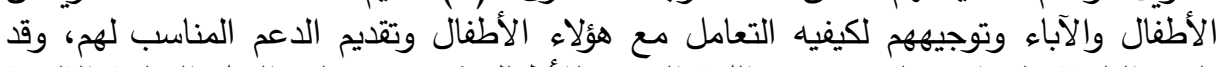

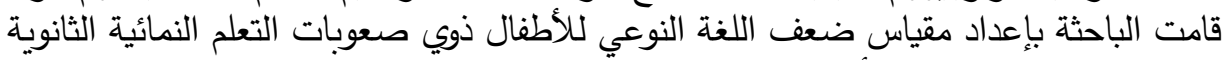
وقد اشتمل المقياس على الأبعاد التالية:

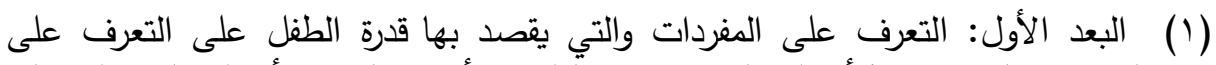

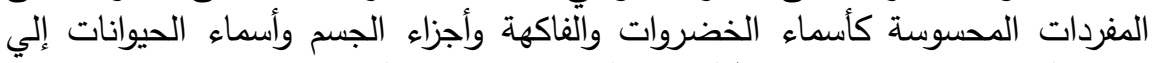

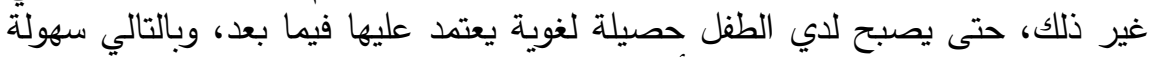

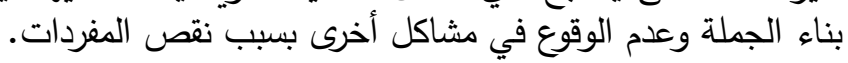
(Y)

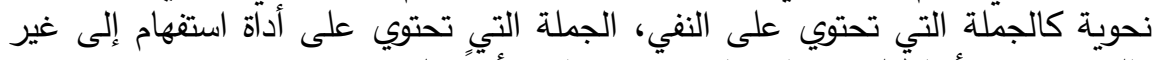

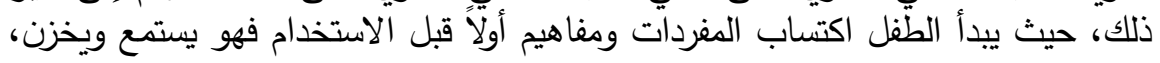
ومن ثم يستخدم المادة المخزنة لديه في التعبير فيما بعد.

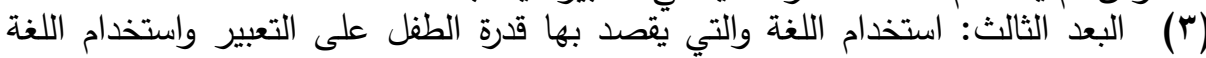

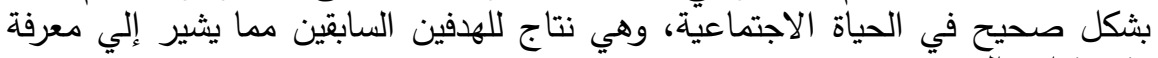

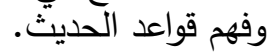

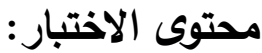

أ- دليل الصور يحتوي على صور ملونة واضحة تستخدم في تطبيق بنود الاختبار .

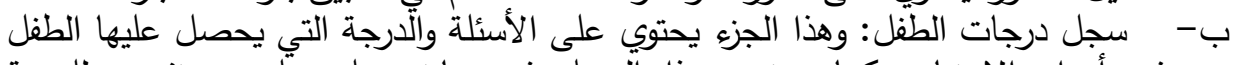

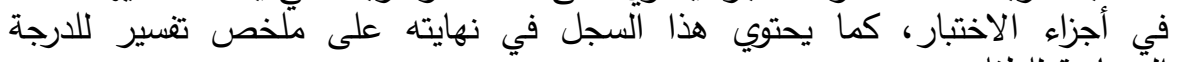

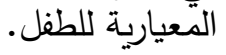


مجلة در اسات فى مجال الإرشاد النفسي و التربوي ـ كلية التربية ـ جامعة أسيوط

\section{تصحيح المقياس:}

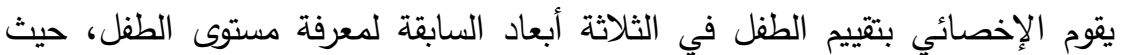

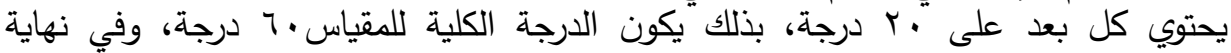
الاختبار يتم حساب الدرجة الكلية، ويوضح جدول (1) تصحيح المقياس وتقدير درجاتة الكلية

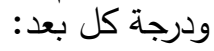

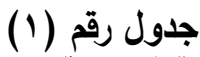

تصحيح المقياس وتقدير الارجات الكلية ودرجة كل بعد

\begin{tabular}{|c|c|c|}
\hline التقدير & الدرجات في كل بعد & الدرجة الكلية \\
\hline شديد & ـ فأقل & ـ ا فأقل \\
\hline متوسط & $9: 0$ & $r 9: 10$ \\
\hline بسيط & $1 \leq: 1$ & $\varepsilon \varepsilon: \mu$. \\
\hline عادى/لا يوجد & $r .: 10$ & $7 .: \leq 0$ \\
\hline
\end{tabular}

الخصائص السيكومترية للمقياس :

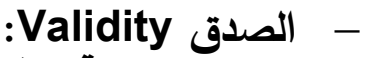

- صدق المقارنة الطرفية (التمييزي):

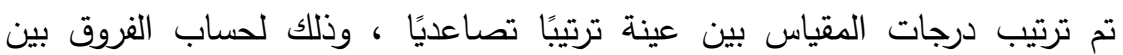

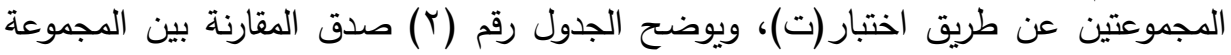
العليا والمجموعة الدنيا على مقياس ضعنف اللغة النوعي.

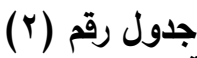

يوضح صدق المقارنة بين المجموعة العليا والمجموعة الدنيا على مقياس ضعف اللغة النوعي

\begin{tabular}{|c|c|c|c|c|c|c|c|}
\hline الحرية & الدلالة & الدالالة & قيمة ت & 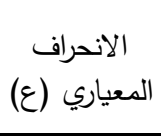 & 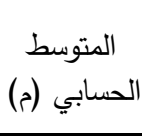 & عدد & \\
\hline \multirow{2}{*}{ rᄉ } & \multirow{2}{*}{$\ldots 0$} & \multirow{2}{*}{$\cdots$} & \multirow{2}{*}{$10 . \leqslant 19$} & 1.1. & ov.A & $r$. & الفئة العليا \\
\hline & & & & $T . \leqslant Y$ & $r \varepsilon . v$ & $r$. & الفئة الدنيا \\
\hline
\end{tabular}

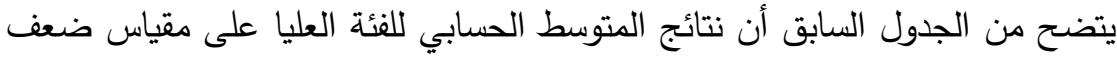

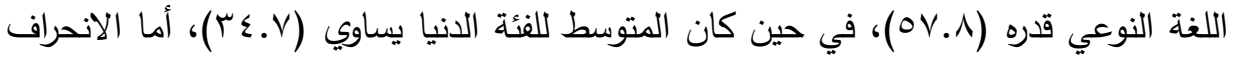

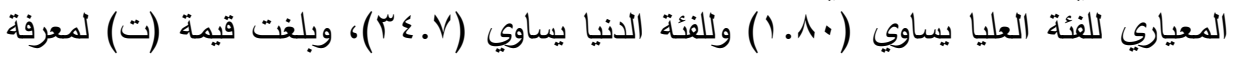

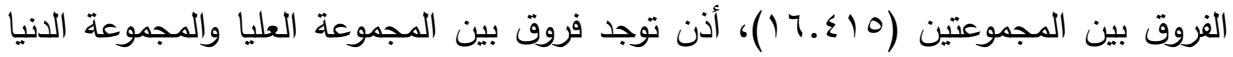

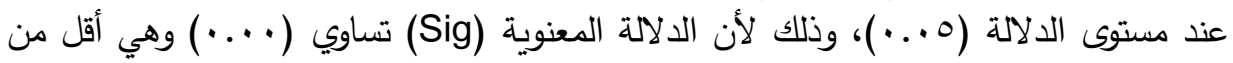
(0.. ) ومن ذلك يتضح أن مقياس ضعف اللغة النوعي يتمتع بدرجة عالية من الصدق. 
ضعـف اللغة النوعي لذوى صعوبات التعلم النمائية الثانوية لمرحلة رياض التراض

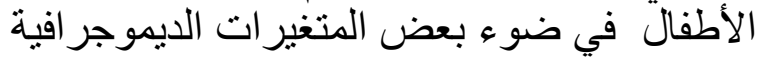

دإمصطفى عبد المحسن الحديبي د/إيمان صلاح الدين حسين الثريف أ/رشا عليوه أحمد عبد النبي

\section{الثبات Reliability}

- - مريقة إعادة تطبيق الاختبار : -

استخدمت طريقة إعادة الاختبار ، لحساب ثبات المقياس بعد تطبيقه بفاصل زمني إلتي

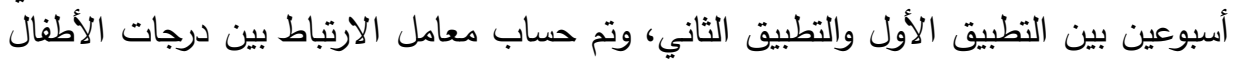

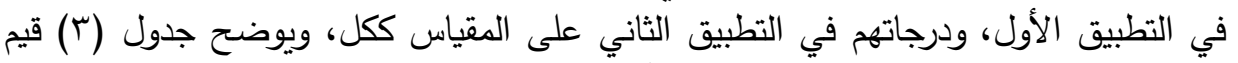
معامل الثبات لمقياس ضعف ودرجاته فللغة النوعي لأطفال الروضة بطريقة إعادة تطبيق الاختبار .

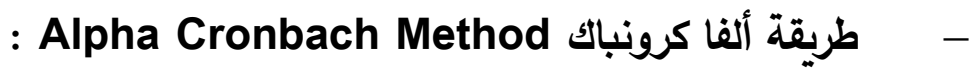

استخدمت طريقة ألفا كرونباك لحساب الثبات لكل من أبعاد المقياس، ويوضح جدول

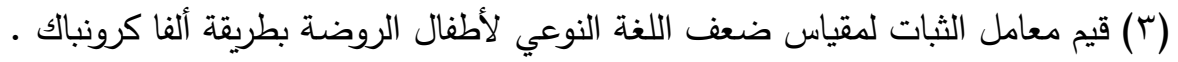

جدول (r)

معاملات الثبات لمقياس ضعف اللغة النوعي بطريقتي إعادة الاختبار وألفا كرونباك

\begin{tabular}{|c|c|c|c|}
\hline \multicolumn{2}{|c|}{ معامل الثبات } & \multirow{2}{*}{ الأبعاد } & \multirow[b]{2}{*}{ 5 } \\
\hline ألفا كرونباك & إعادة تطبيق الاختبار & & \\
\hline$\therefore \vee \wedge$ &..$\Lambda Y$ & أولاً: التعرف على المفردات & 1 \\
\hline. .10 &. .10 & ثانياً: فهم الجملة & $r$ \\
\hline..$\wedge \Lambda$ &.$\wedge$. & ثالثا: استخدام اللغة أو التعبير & $r$ \\
\hline. .91 &.. $\mathrm{Ar}$ & مل الثبات لمقياس ككل & \\
\hline
\end{tabular}

يتضح من جدول (Y) أن معاملات الثبات مرتفعة لمقياس ضعف اللغة النوعي وأبعاده

$$
\begin{aligned}
& \text { الثلاثة، وهي قيم ثبات مطنئنة . } \\
& \text { نتائج الدراسة ومناقشتها : } \\
& \text { 1-نتائج الفرض الأول وتفسيرها : }
\end{aligned}
$$

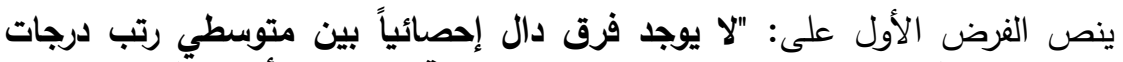

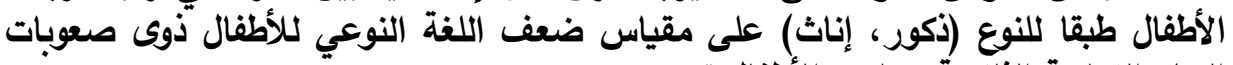

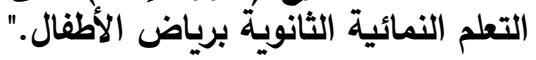

للتحقق من صحة هذا الفرض قامت الباحثة بحساب المتوسط الحسابي والانحراف

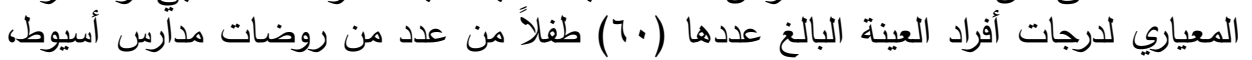

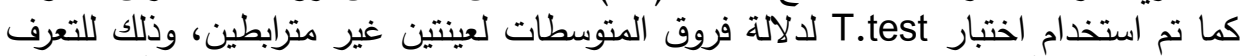

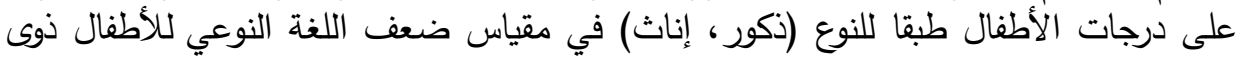


مجلة دراسات فى مجال الإرشاد النفسي و التربوي ـ كلية التربية ـ جامعة أسيوط

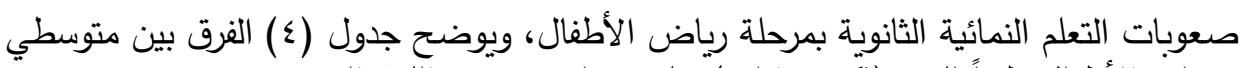

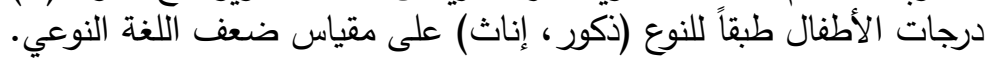

$$
\text { جدول (ع ( ) }
$$

الفرق بين متوسطي رتب درجات الأطفال طبقا للنوع (ذكور، إناث) في مقياس ضعف اللغة النوعي (ن= • ؟َ)

\begin{tabular}{|c|c|c|c|c|c|c|}
\hline \multirow[b]{2}{*}{ قيمة ت } & \multicolumn{2}{|c|}{ الإناث (ن=YYY) } & \multicolumn{2}{|c|}{ الذكور (ن=ء } & \multirow[b]{2}{*}{ الأبعاد } & \multirow[b]{2}{*}{ r } \\
\hline & $\begin{array}{r}\text { الانحراف } \\
\text { المعياري }\end{array}$ & الحسابي (م) & الانحياري (ع) & الحسابي (م) & & \\
\hline NSI. $\leqslant 7$ & $1.9 \mathrm{~V}$ & $1 V .9 Y$ & T.TV & $1 V . .0$ & التعرف على المفردات & 1 \\
\hline NSI. $1 \varepsilon$ & 1.199 & 10.0 & r.r. & $1 \leq . \vee \cdot$ & فهم الجملة & r \\
\hline NS 1.99 & 1.19 & 11.1. & T.tr & $1 . . \vee 9$ & استخدام اللغة & r \\
\hline
\end{tabular}

يتضح مما سبق وجود فرق بين عدد الأطفال طبقا للنوع (ذكور، إناث) على مقياس

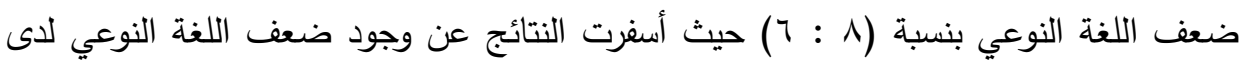

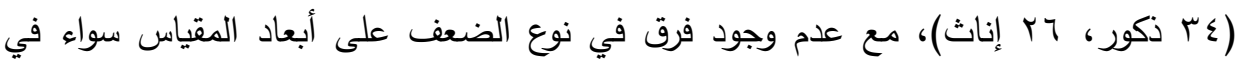

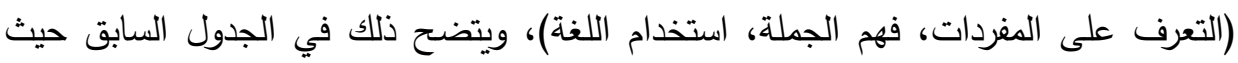

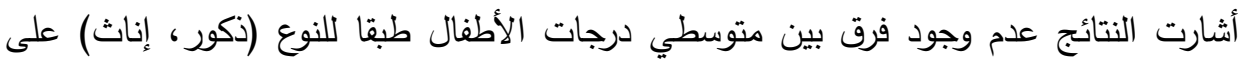

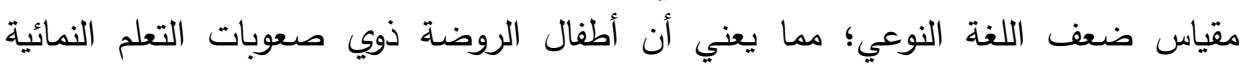
متساوون في معاناتهم من نوع ضعف اللغة النوعي بغض النظر النغ عن النوع (ذكور وإناث) .

\section{r - نتائج الفرض الثاني وتفسيرها :}

ينص الفرض الثاني على: " لا يوجد فرق دال إحصائياً بين المراحل العمرية (Kg1) (Kg2) على مقياس ضعف اللغة النوعي لذوى صعوبات التعلم النمائية الثانوية بمرحلة الأية رياض الأطفال " . معياض

للتحقق من صحة هذا الفرض تم استخدام اختبار T.test لدلالة فروق المتوسطات

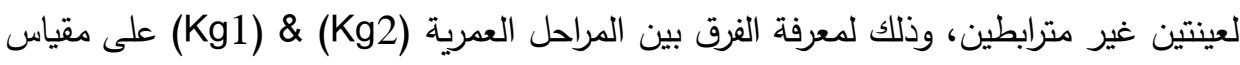

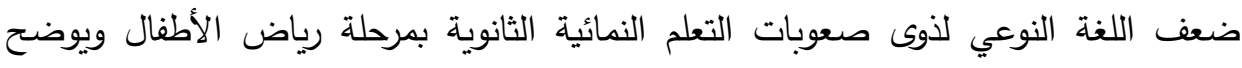

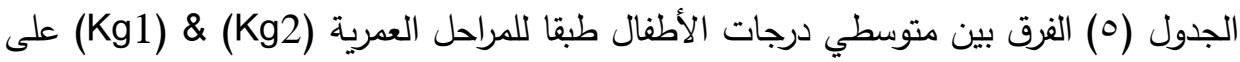
مقياس ضعف اللغة النوعي، وهذا يتضح في الجدول التالي : 
ضعـف اللغة النوعي لذوى صعوبات التعلم النمائية الثانوية لمرحلة رياض التراض

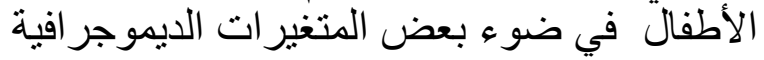

دامصطفى عبد المحسن الحديبي د/إيمان صلاح الدين حسين الثريف أ/رشا عليوه أحمد عبد النبي

\section{جدول (0)}

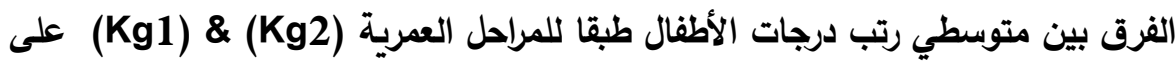
مقياس ضعف اللغة النوعي (ن= • ؟7)

\begin{tabular}{|c|c|c|c|c|c|c|}
\hline \multirow[b]{2}{*}{ ق قيمة ت } & \multicolumn{2}{|c|}{$\mathrm{Kg} 2$} & \multicolumn{2}{|c|}{ Kg1 } & \multirow[b]{2}{*}{ الأبعاد } & \multirow[b]{2}{*}{5} \\
\hline & $\begin{array}{c}\text { الانحرافياري } \\
\text { المعيار) }\end{array}$ & الحسابي (م) & $\begin{array}{c}\text { الانحرافي } \\
\text { المعياري }\end{array}$ & $\begin{array}{l}\text { الحسابي } \\
\text { المتوسط (م) }\end{array}$ & & \\
\hline NSI. . $\varepsilon$ & 1.9. & 11 & T.TA & 17.97 & التعرف على المغردات & 1 \\
\hline NS 1.99 & $1 . V V$ & $10.0 \mathrm{~V}$ & t.rT & $1 \varepsilon .09$ & فهم الجملة & $r$ \\
\hline NST.I & $1 . r_{0}$ & $11 . \wedge r$ & T.TV & $1 . . v 1$ & استخدام اللغة (التعبير ) & r \\
\hline
\end{tabular}

يتضح مما سبق وجود فرق بين عدد الأطفال طبقا المراحل العمرية (KG1)، وKG2)

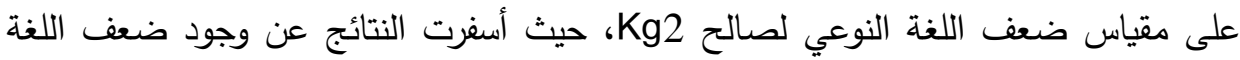

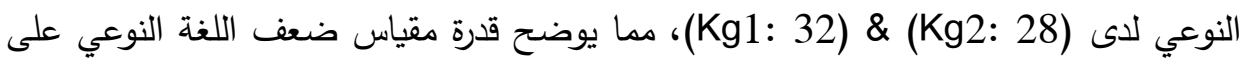

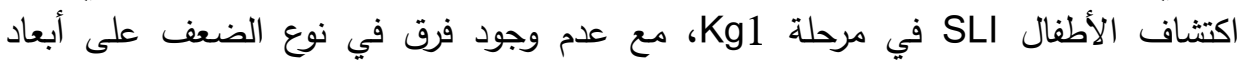

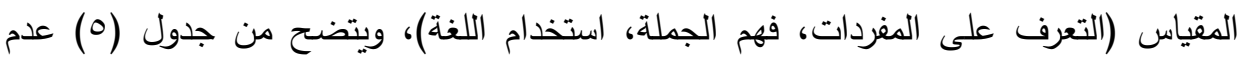

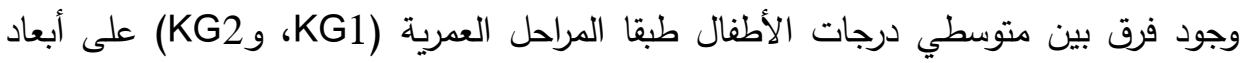

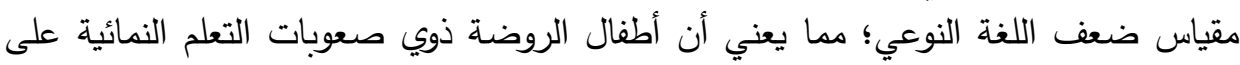

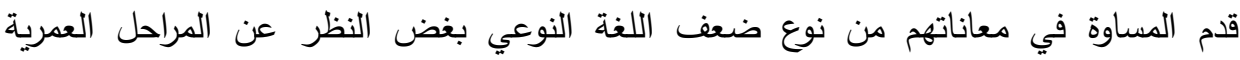
. (KG2, و

\section{تعقيب على نتائج الدراسة :}

المستقرئ لنتائج فرضي الدراسة الأول والثاني يتضح له أن أطفال الروضة الذين يعانون

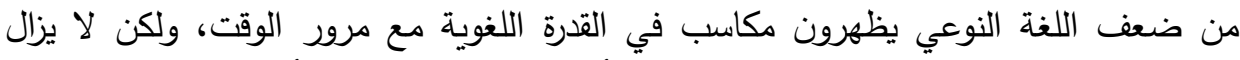

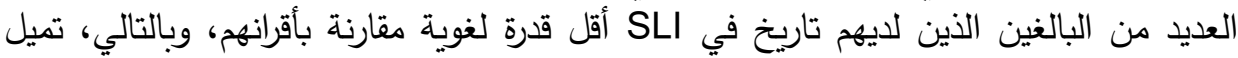

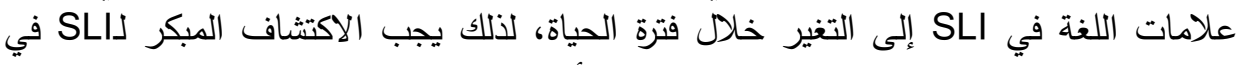

مرحلة الطفولة المبكرة حيث تكون المشاكل اللغوية أكثر وضوحًا (خاصة في استخدام اللغة). توصيات الدراسة

1- تدريب المعلمات على اكتثاف الأطفال ذو ضعف اللغة النوعي وكيفيه التعامل معهم . 
مجلة دراسات فى مجال الإرشاد النفسي و التربوي ـ كلية التربية ـ جامعة أسيوط

r- تدريب الوالدين على التعرف على الأطفال الذين يعانون من ضعف اللغة النوعي وكيفيه

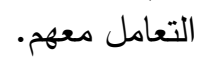

ب- إقامة برامج توعوية للمجتمع للتعرف على الأطفال ذوي ضعف اللغة النوعي .

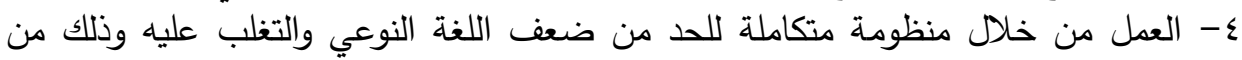

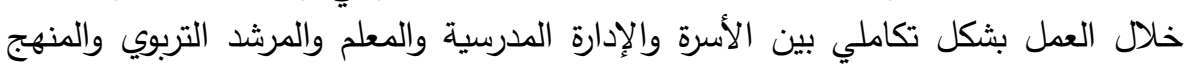

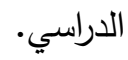




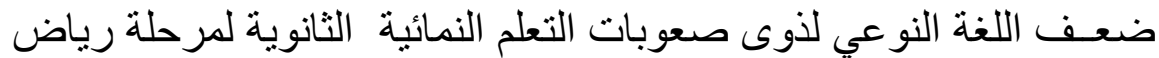

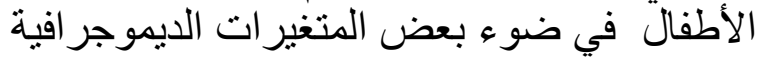

دامصطفى عبد المحسن الحديبي د/إيمان صلاح الدين حسين الثريف أ/رشا عليوه أحمد عبد النبي

\section{قائمة المراجع}

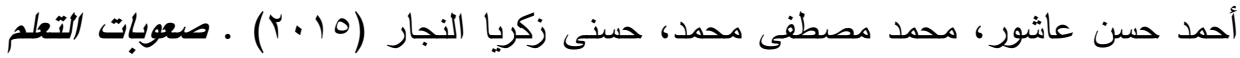
النمائية، عمان : دار المسيرة للنشر والتوزيع والطباعة .

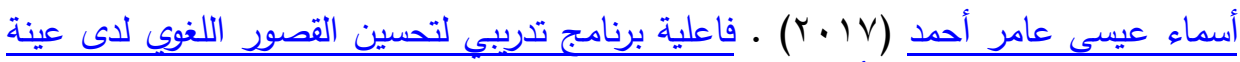

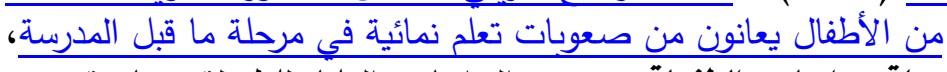

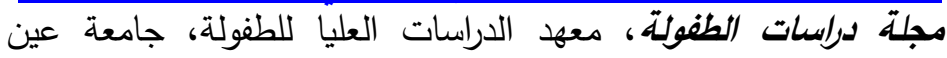

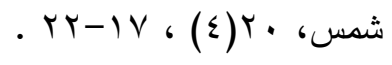

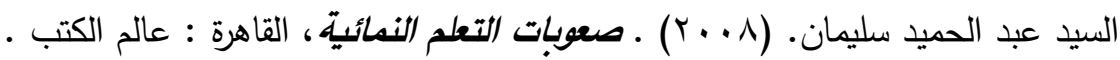

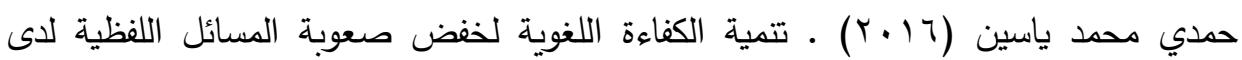

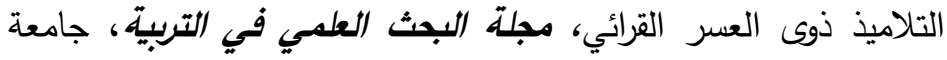

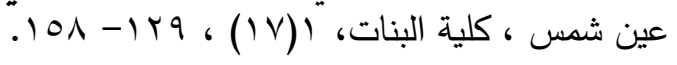

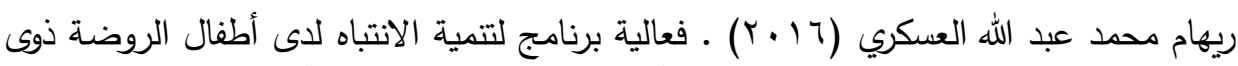

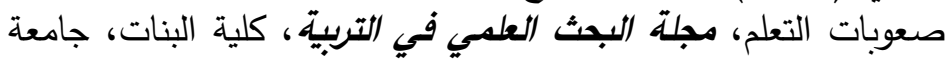

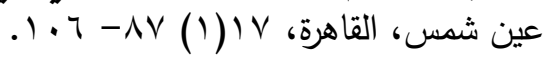

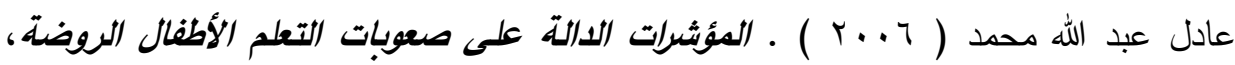
القاهرة : دار الرشاد . المغرات

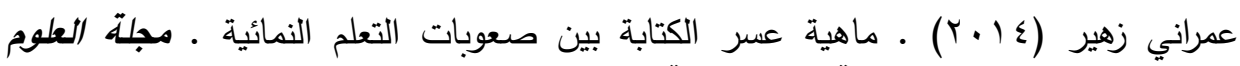

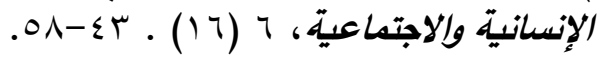

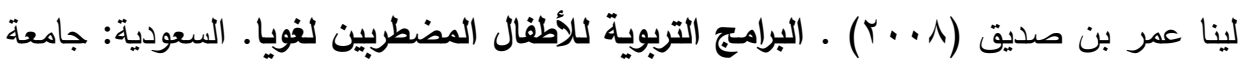

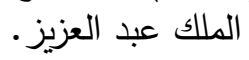

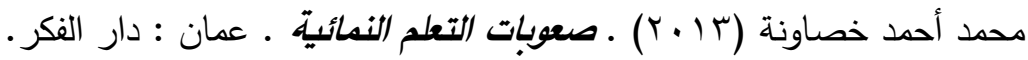

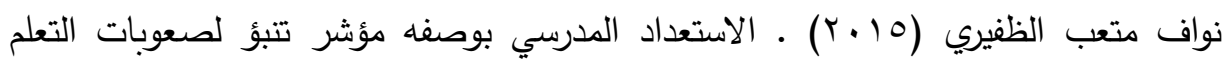

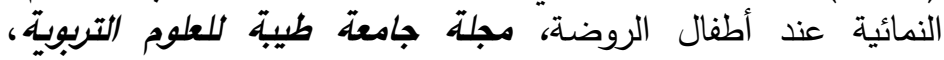

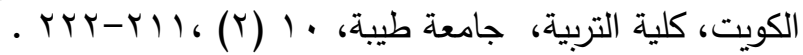


مجلة در اسات فى مجال الإرشاد النفسي و التربوي ـ كلية التربية ـ جامعة أسيوط

Czaplewska, E., Kochańska, M., Maryniak, A., Haman, E., \& Smoczyńska, M. (2014). SLI-specyficzne zaburzenie językowe. Podstawowe informacje dla rodziców i nauczycieli.

Evans, J., \& Brown, T. (2016). Specific language impairment. In Neurobiology of language (pp. 899-912). Academic Press.

Ghayoumi-Anaraki, Z., Haresabadi, F., Maleki Shahmahmood, T., Ebadi, A., Vakili, V., \& Majidi, Z. (2017) . The Grammatical Deficits of Persian-Speaking Children with Specific Language Impairment . Journal of Rehabilitation Sciences \& Research, 4(4), 102-108.

Grist. M ., Knowles L ., Lascelles L ., Huneke A . (2012) : The Sli Handbook . London .

Henry, L., Messer, D., \& Nash, G. (2012). Executive functioning in children with specific language impairment. Journal of child psychology and psychiatry, 53(1), 37-45.

Lahtinen, S., \& Laurila, S. (2019). Lapsen puheen kehitys sekä yleisimmät puheen ja kielen häiriöt-oppimateriaali . Opinnäytetyö Kevät . Oulun ammattikorkeakoulu .

Oryadi-Zanjani, M., Vahab, M., Rasouli, J., Ashkbousi, R., \& Barpoosh, N. (2015). The Prevalence of Specific Language Impairment in 5-year-old Persian-Speaking Children in Shiraz City of Iran-2015. Journal of Rehabilitation Sciences and Research, 2(4), 93-96.

Prelock, P., \& Hutchins, T. (2018). Clinical Guide to Assessment and Treatment of Communication Disorders. Springer International Publishing.

Rice M., (2017) . Specific language impairment: What do we know?, National Institute on Deafness and Other Communication Disorders (NIDCD) , August, 34-35.

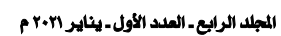

https://dapt.journals.ekb.eg
111 


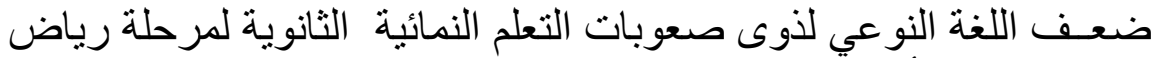

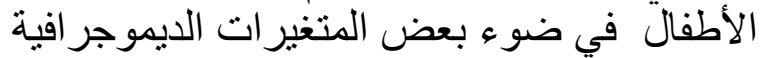

دأدصطفى عبد المحسن الحديبي د/إيمان صلاح الدين حسين الثريف أ/رشا عليوه

أحمد عبد النبي

Rudolph, J., \& Leonard, L. (2016). Early language milestones and specific language impairment. Journal of Early Intervention, 38(1), 41-58.

Reilly, S., Tomblin, B., Law, J., McKean, C., Mensah, F., Morgan, A., \& Wake, M. (2014). Specific language impairment: a convenient label for whom?. International Journal of Language \& Communication Disorders, Australia, 49(4), 416-451.

Snowling, M., Bishop, D., Stothard, S., Chipchase, B., \& Kaplan, C. (2006) . Psychosocial outcomes at 15 years of children with a preschool history of speech-language impairment, Journal of Child Psychology and Psychiatry, 47(8): 759-765.

Szukiel, B., Górska, M., \& Kruk, U. (2017). Differential Diagnosis of Specific Language Impairment-SLI. Polish Journal of Applied Sciences, 3(1), 5-10.

Tomblin, J., Records, N., Buckwalter, P., Zhang, X., Smith, E., \& O'Brien, M. (2016). Prevalence of specific language impairment in kindergarten children. Journal of speech, language, and hearing research, Author manuscript, HHS Public Access, 40(6), 1245-1260.

Thordardottir, E., \& Weismer, S. (2002). Verb argument structure weakness in specific language impairment in relation to age and utterance length. Clinical linguistics \& phonetics, McGill University, Montreal, Canada 16(4), 233-250.

Tumanova, T., \& Filicheva, T. (2017). Russian Scientific Trends on Specific Language Impairment in Childhood. In Advances in Speech-language Pathology. IntechOpen. 